\title{
As sementes de Eugenia spp. (Myrtaceae) e seus novos conceitos sobre propagação
}

Submetido: 09.04.2020; aceito: 03.09.2020

Como citar: Amorim, I.P., Silva, J.P.N., \& Barbedo, C.J. 2020. As sementes de Eugenia spp. (Myrtaceae) e seus novos conceitos sobre propagação. Hoehnea 47: e292020. http://dx.doi.org/10.1590/2236-8906-29/2020.

ABSTRACT - (Eugenia spp. (Myrtaceae) seeds and their new concepts about propagation). The standard behavior expected for seeds, whether by inexpert or even experts on the subject, is that of a dry structure that, when placed in a medium with sufficient water availability, germinates and produces a new plant, thus perpetuating the species. However, there is a huge number of species with recalcitrant seeds which the behavior is totally different. They cannot be dried, are shed moist in the environment and, along the evolution of the species, have developed alternative systems to guarantee their propagation. In this review, we seek to demonstrate one of the most complex and interesting systems for the preservation of species with recalcitrant seeds, focusing on species of the genus Eugenia, of the Myrtaceae family. Both the ability to regenerate embryos from cotyledonary tissues and the extremely efficient control in not wasting reserve material are addressed, avoiding simultaneous germination in the same seed. Reactive oxygen species (ROS) seem to be involved in this control, which are also reviewed in this article.

Keywords: ecological strategy, reactive oxygen species, recalcitrant seeds

RESUMO - (As sementes de Eugenia spp. (Myrtaceae) e seus novos conceitos sobre propagação). O comportamento padrão esperado para as sementes, seja por leigos ou mesmo especialistas no assunto, é o de uma estrutura seca que, colocada em meio com suficiente disponibilidade de água, germina e produz uma nova planta, preservando a espécie. Contudo, há um gigantesco número de espécies que possuem sementes com comportamento totalmente diferente. Sementes que não podem sequer serem secas, denominadas recalcitrantes, são dispersas úmidas no meio e, ao longo da evolução das espécies, desenvolveram sistemas alternativos àqueles padrões esperados. Nesta revisão, procuramos demonstrar um dos mais complexos e interessantes sistemas de preservação de espécies com sementes recalcitrantes, nas espécies do gênero Eugenia, da família Myrtaceae. São abordados tanto a capacidade em regenerar embriões a partir de tecidos cotiledonares, quanto o controle extremamente eficiente em não desperdiçar material de reserva, evitando germinações simultâneas na mesma semente. Neste controle parecem estar envolvidas as espécies reativas de oxigênio (EROs), que também são revistas neste artigo. Palavras-chave: espécies reativas de oxigênio, estratégia ecológica, sementes recalcitrantes

\section{Introdução}

Há cerca de 20 anos, dois pesquisadores estudaram as sementes de Eugenia stipitata ssp. sororia McVaugh (Anjos \& Ferraz 1999), popularmente conhecida como araçá-boi, uma espécie amazônica com grande potencial de aproveitamento econômico (Flores \& Clement 1984).
Essas sementes já eram conhecidas por sua intolerância à dessecação (recalcitrantes) e por ter tegumento resistente que causava atrasos na germinação (Gentil \& Ferreira 1999).

Buscando conhecer a morfologia das sementes para fornecer subsídios que permitisse seu melhor aproveitamento na produção de mudas, aqueles autores notaram que seu único embrião não apresentava eixo embrionário distinto

1. Instituto de Botânica, Núcleo de Pesquisa em Sementes, Avenida Miguel Stéfano, 3687, 04301-012 São Paulo, SP, Brasil

2. Instituto Butantan, Núcleo Estratégico de Venenos e Antivenenos, Biotério de Artrópodes, Avenida Vital Brazil, 1500, 05503-900 São Paulo, SP, Brasil

3. Autor para correspondência: cjbarbedo@yahoo.com.br 
visível, sendo composto apenas pela massa cotiledonar volumosa e branco-leitosa. Contudo, encontraram também algo surpreendente: a capacidade regenerativa do embrião quando suprimido de parte de seus tecidos (Anjos \& Ferraz 1999). Nesse momento, abria-se uma nova linha de estudos e uma verdadeira revolução nos conceitos acerca da fisiologia e ecologia de sementes. Cada vez mais, os estudos que se seguiram com sementes de espécies de Eugenia desvendavam novos comportamentos.

Outros autores também demonstraram a ausência de distinção visível entre o eixo hipocótilo-radicular e os cotilédones em sementes de Eugenia (Andrade \& Ferreira 2000, Lucas et al. 2005). Essa dificuldade em localizar o eixo levou alguns autores a aceitarem a hipótese de que estas sementes são compostas por embriões conferruminados (Barroso et al. 1999). Porém, em E. pyriformis Cambess. foi possível constatar que, embora o eixo embrionário não seja visível a olho nu, com o auxílio de lupa de pequeno aumento é possível identificar o polo embrionário em uma das extremidades da cicatriz rafeal na superfície dos cotilédones (Justo et al. 2007).

Portanto, a obtenção de mais de uma raiz, ou mesmo plântulas completas, a partir de uma única semente de Eugenia, como observado em trabalhos posteriores (Silva et al. 2003, 2005), é resultado não da existência de mais de um embrião em cada semente, mas da capacidade que cada semente tem em diferenciar novos embriões (Delgado et al. 2010). Neste trabalho, procurou-se concentrar as informações produzidas em mais de 20 anos de estudo sobre essa raríssima capacidade das sementes de Eugenia, demonstrando o histórico da evolução desse conhecimento e identificando-se sua origem, seu controle e suas vantagens ecológicas.

\section{Importância e características de Myrtaceae e Eugenia spp.}

O Brasil é mundialmente reconhecido por sua imensa diversidade biológica, principalmente por sua flora, sendo considerado um dos principais centros de diversidade genética em espécies frutíferas do mundo (Pereira et al. 2012). E, ainda que na Amazônia e no Cerrado encontrese uma maior variedade de espécies de frutas nativas, a região sul também detém uma grande riqueza em frutos silvestres, dentre os quais a família Myrtaceae ocupa um lugar de destaque, apresentando o maior número de espécies com potencial alimentício que, inclusive por suas inúmeras propriedades medicinais, poderiam ser comercializadas in natura ou para uso na fabricação de sucos, sorvetes, iogurtes, licores, doces, geleias etc. (Pereira et al. 2012).

Muitos frutos de mirtáceas são agradáveis visualmente e ao paladar (figura 1), mas se destacam principalmente por seu potencial medicinal. A pitanga (Eugenia uniflora L.), por exemplo, é utilizada há muito tempo na medicina popular para diferentes fins. Seus frutos, incluindo suas sementes, são ricos em cálcio, fósforo, antocianina, flavonoides, carotenoides e vitamina $\mathrm{C}$, que indicam sua alta propriedade antioxidante (Franzon et al. 2018). O elevado consumo de frutos e outros vegetais com potencial antioxidativo pode estar associado a uma incidência reduzida de certos tipos de cânceres e a efeitos benéficos em doenças cardiovasculares, diabetes, obesidade e catarata (Steinmetz \& Potter 1996, Ratnam et al. 2006, Pereira 2012).

Os frutos de grumixama (Eugenia brasiliensis) também são conhecidos como uma fonte rica em compostos benéficos para a saúde, podendo estar associados à redução do risco de desenvolvimento de doenças crônicas, distúrbios tumorais, doenças cardiovasculares, diabetes tipo II e outros distúrbios inflamatórios crônicos (Teixeira et al. 2018). Os principais compostos bioativos encontrados na grumixama são flavonoides, elagitaninos e carotenoides (Okuda et al. 1982, Reynertson et al. 2008, Abe et al. 2012, Fracassetti et al. 2013). Outro exemplo são os frutos de uvaia (Eugenia pyriformis), considerados uma ótima fonte de ferro e zinco, além de possuírem um alto teor de vitamina $\mathrm{C}$, compostos fenólicos e carotenoides, igualmente constituindo uma fonte rica em antioxidantes (Pereira et al. 2014, Silva et al. 2018).

Os frutos da família Myrtaceae podem proporcionar uma maior variedade à dieta de um público de consumidores mais conscientes que buscam por alimentos saudáveis, fornecendo antioxidantes naturais que protegem o organismo dessas doenças e do envelhecimento precoce (Pereira et al. 2012). E o aumento na produção desses frutos também pode torná-los acessíveis às populações mais pobres, que atualmente possuem um estado de saúde inferior ao das classes sociais mais altas, fato que está relacionado à qualidade inadequada de sua dieta, caracterizada pelo consumo insuficiente de hortaliças e frutos (Coelho et al. 2009). A produção e a construção de conhecimentos que unem as dimensões ambientais, sociais, culturais e de saúde, bem como a divulgação dessas informações para o público leigo, também podem favorecer a utilização destes frutos nativos na alimentação popular.

De fato, estudos sobre segurança alimentar e nutricional buscam reverter a tendência mundial de expansão das monoculturas de commodities, promovendo modelos de agricultura diversificados, equitativos e nutritivos (Keple 2014). Ao promover a inclusão desses produtos florestais nativos do Brasil em mercados, através de práticas sustentáveis e produção de alimentos de ampla qualidade, além da conservação da biodiversidade, fomentase a manutenção de valores socioambientais associados (Cadeias 2019), pois mais da metade da população de municípios com maior cobertura vegetal do Brasil vive em condições de pobreza (Kasecker et al. 2017). Estas iniciativas resguardariam, portanto, o protagonismo das famílias agricultoras e extrativistas, gerando renda e reduzindo a pobreza.

As espécies frutíferas nativas ainda são importantes para a recuperação de áreas degradadas, uma vez que seus frutos 


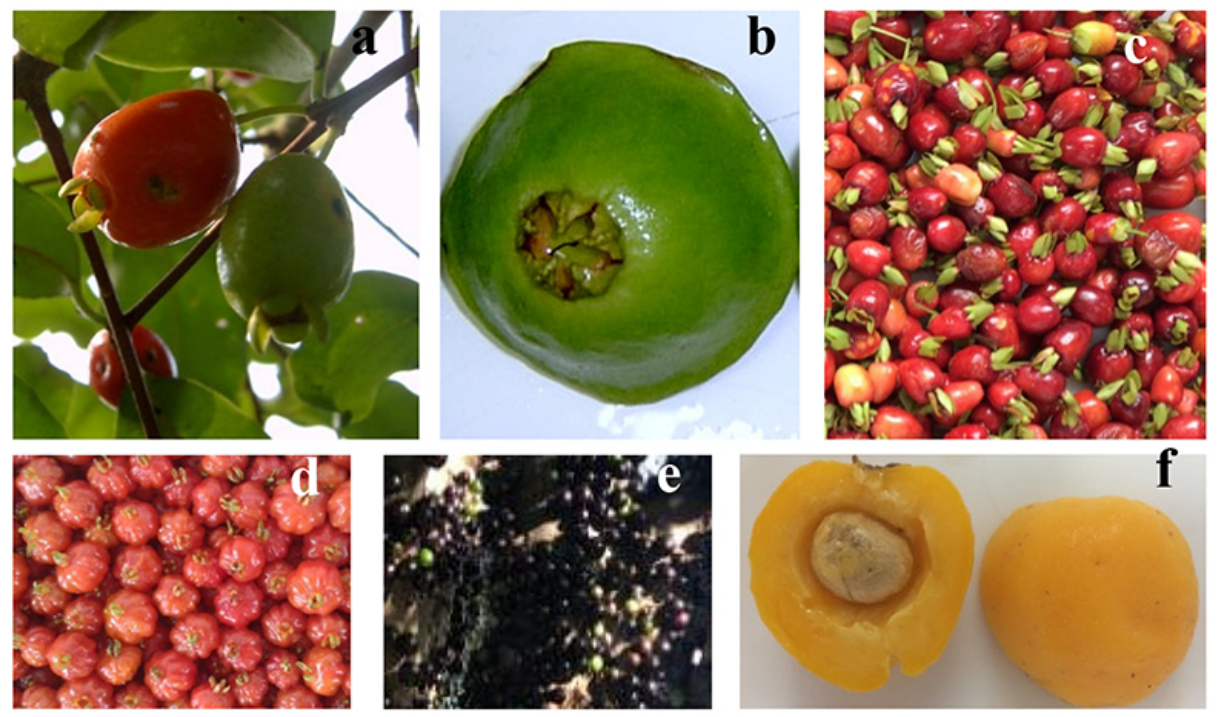

Figura 1. Frutos de espécies de Myrtaceae. a. Eugenia cerasiflora Miq. - guamirim. b. Campomanesia phaea (O.Berg) Landrum - cambuci, c. Eugenia involucrata DC. - cereja do Rio Grande, d. Eugenia uniflora L. - pitanga, e. Myrciaria cauliflora (Mart.) O. Berg. - jabuticaba, f. Eugenia pyriformis Cambess. - uvaia.

Figure 1. Fruits of Myrtaceae species. a. Eugenia cerasiflora Miq. - guamirim, b. Campomanesia phaea (O. Berg.) Landrum - cambuci. c. Eugenia involucrata DC. - cherry of Rio Grande. d. Eugenia uniflora L. - Suriname cherry. e. Myrciaria cauliflora (Mart.) O. Berg.jabuticaba. f. Eugenia pyriformis Cambess. - uvaia.

são atrativos para a fauna local, principalmente para aves e macacos, mas também para lagartos, morcegos, roedores, peixes etc. (Pizzo 2002, Castro \& Galetti 2004, Gressler et al. 2006). Contudo, um dos maiores obstáculos para a produção comercial de diversos produtos florestais, ou até mesmo para a restauração de áreas degradadas, é a indisponibilidade, em quantidade suficiente, de sementes de espécies florestais nativas do Brasil (Calvi et al. 2016, Barbosa et al. 2018, Piña-Rodrigues et al. 2018). Muitas espécies de Myrtaceae, especialmente as de Eugenia, apresentam baixa densidade de ocorrência natural, além de muitas delas produzirem frutos com poucas sementes, frequentemente uma ou duas, dificultando a obtenção de quantidades suficientes que permitam a produção de mudas em larga escala (Silva $e t$ al. 2005 e referências contidas).

A família Myrtaceae Juss., descrita pela primeira vez em 1789 por Jussieu, em sua obra Genera Plantarum, possui distribuição predominantemente pantropical e subtropical, incluindo cerca de 130 gêneros e 4.000 espécies. No Brasil, as mirtáceas possuem uma grande representatividade, com 22 gêneros e aproximadamente 1.000 espécies (Souza $\&$ Lorenzi 2012). Atualmente, a família é uma das mais complexas do ponto de vista taxonômico, tanto pelo número de espécies e pela escassez de estudos, quanto pela utilização de caracteres complexos na sua identificação, como, por exemplo, o tipo de embrião na distinção de grandes grupos (Souza \& Lorenzi 2012).

Segundo McVaugh (1956), os representantes americanos da família Myrtaceae eram considerados um grupo ainda mais difícil e carente de estudos sistemáticos, e isso se devia, em parte, ao grande número de espécies nos trópicos americanos e, em parte, a certas características particulares das próprias plantas. A identificação do material floral já era bastante difícil, uma vez que as distinções entre gêneros foram feitas principalmente com base em caracteres do embrião maduro. Além disso, em material seco as identificações se tornam um desafio. Se mesmo nos espécimes com frutos maduros os caracteres dos embriões nem sempre são fáceis de serem observados, naquelas ainda em floração isso se torna quase impossível (McVaugh 1956).

De Candolle (1828) reconheceu as mirtáceas americanas, aquelas cujos frutos eram carnosos, como uma tribo, que ele chamou de Myrteae. Suas contribuições, e de Berg (185562), foram fundamentais para o conhecimento das espécies e gêneros de Myrteae. O autor também dividiu boa parte de Myrteae em três grupos principais, Myrciinae, Eugeniinae e Pimentinae (que, posteriormente, foram caracterizados por Berg como subtribos, Eugeniinae, Myrciinae e Myrtiinae), baseando-se, de novo, na morfologia dos embriões desses grupos (De Candolle 1828).

Estudos com Myrtaceae continuam representando um grande desafio, e as identificações genéricas, feitas muitas vezes com caracteres ambíguos, podem desencorajar pesquisadores em potencial. A divisão de Myrteae nas três subtribos Eugeniinae, Myrciinae e Myrtiinae com base na morfologia dos embriões, ainda que complexa, continuou sendo aceita, e a grande variação nos frutos e nas sementes do gênero Eugenia geraram um interesse particular (Landrum \& Kawasaki 1997). De acordo com Berg, as espécies de mirtáceas americanas conhecidas compreendiam um total 
de 1.726, das quais ele próprio propôs 1.008, com Eugenia já representando um dos gêneros mais diversos, contendo, sozinho, 537 espécies (McVaugh 1956).

A subtribo Eugeniinae, que compreende o gênero Eugenia, é caracterizada por seus embriões eugenioides, constituídos por duas formas básicas: (1) cotilédones grossos, separados, plano-convexos e hipocótilo em uma pequena protrusão; e (2) cotilédones fundidos parcial ou completamente em uma única massa e hipocótilo nãodistinguível (Landrum \& Kawasaki 1997). E Eugenia, ainda hoje, é considerado o maior gênero de Myrtaceae neotropical (Mazine et al. 2018), sendo o gênero de angiospermas com maior número de espécies no Brasil (BFG 2015) e o segundo gênero de árvores mais diverso em espécies do mundo (Beech et al. 2017), compreendendo atualmente cerca de 1.100 espécies (WCSP 2017).

\section{As sementes de Eugenia spp.}

As sementes de Eugenia são dispersas com altos teores de água e são recalcitrantes, não conseguindo, portanto, manterem-se viáveis por longos períodos em armazenamento (Flores \& Clement 1984, Flores \& Rivera 1989, Gentil \& Ferreira 1999, Delgado \& Barbedo 2007). No entanto, Inocente \& Barbedo (2019) demonstraram que, ainda que sejam sensíveis à dessecação, as sementes de Eugenia são tolerantes ao déficit hídrico, tornando-as capazes de superar algumas condições adversas que podem encontrar na natureza ao serem dispersas, como a pouca disponibilidade de água no solo. São sementes exalbuminosas, ocupando toda a cavidade delimitada pelo envoltório e consomem todo o seu endosperma ao longo do desenvolvimento (Flores \& Rivera 1989). Possuem um único embrião, ainda que a poliembrionia seja uma característica muito comum e amplamente estudada para alguns gêneros de mirtáceas (Johnson 1936, Litz 1984). Mas, ainda que a delimitação de espécies em Eugenia seja controversa, a maioria dos estudos confirmam a monoembrionia no gênero e sugere que as espécies com sementes poliembriônicas devem ser incluídas no gênero Syzygium (Gurgel \& Soubihe-Sobrinho 1951, Van Wyk \& Botha 1984, Lughadha \& Proença 1996).

Além disso, as sementes de Eugenia são muito resistentes a danos físicos e, quando fracionadas, mantêm sua capacidade de germinar e de produzir plântulas em mais de uma fração (figura 2). Um comportamento semelhante também já foi observado em sementes recalcitrantes de Garcinia e de Allanblackia, da família Clusiaceae, que demonstram uma capacidade regenerativa após serem fracionadas (Ha et al. 1988, Malik et al. 2005, Joshi et al. 2006, Asomaning et al. 2011, Ofori et al. 2015). Contudo, ainda que sementes de Garcinia spp. que passaram por algum tipo de dano físico tenham demonstrado melhores chances de germinar do que aquelas que foram mantidas sem nenhum dano (Joshi et al. 2006), elas são agamospérmicas, pois o embrião, não zigótico, se desenvolve sem fertilização (Ha et al. 1988). Já a regeneração em sementes fracionadas de Eugenia ocorre a partir da desdiferenciação de células de tecidos perivasculares localizados na região apical dos cotilédones, demonstrando que as novas plantas produzidas apresentam genoma diferente da planta-mãe e idêntico ao do embrião
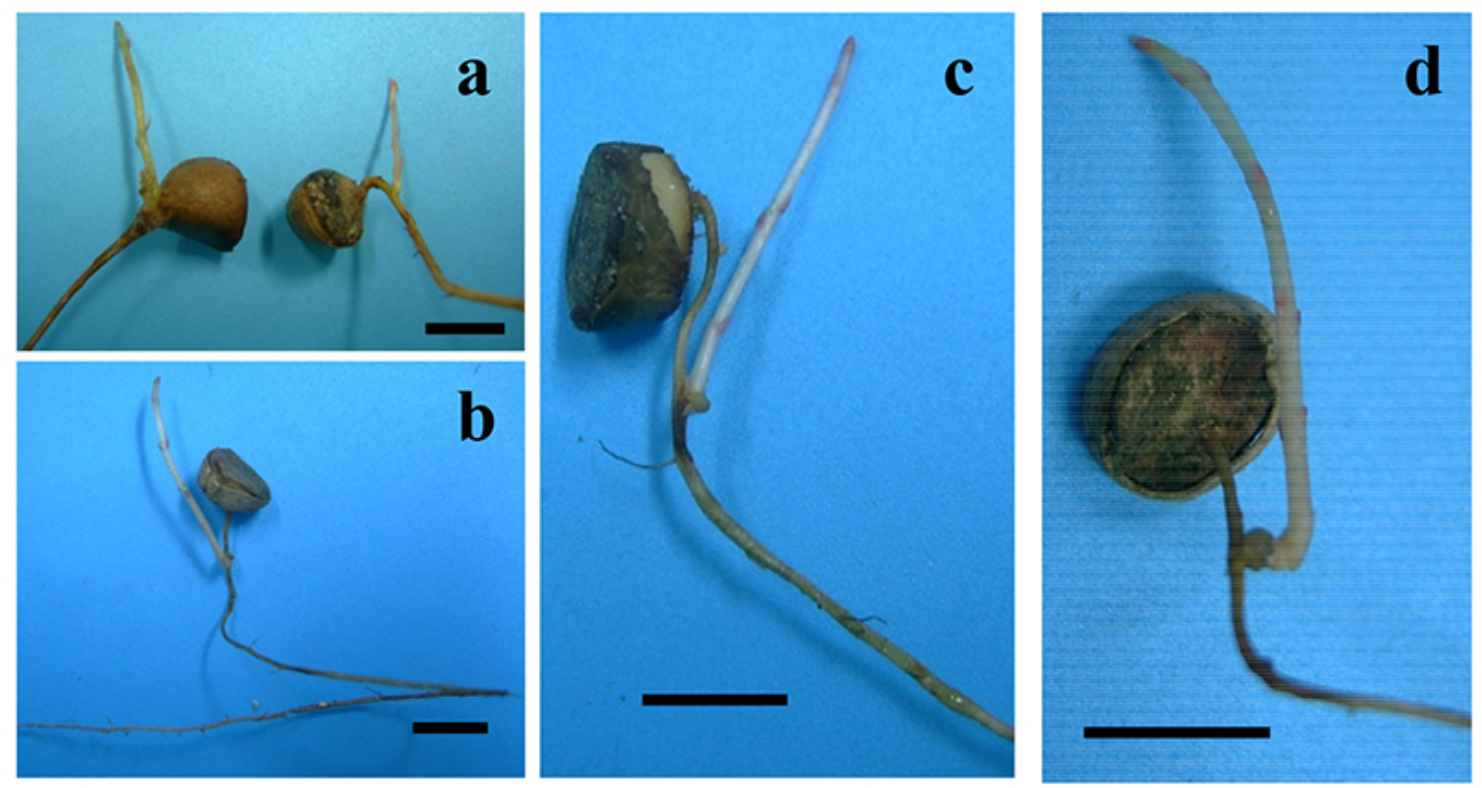

Figura 2. Sementes de Eugenia dysenterica DC. (cagaita) fragmentadas e germinando. a. duas metades da mesma semente, cada uma produzindo uma plântula normal. b-d. produção de uma plântula a partir de tecidos da raiz. Note, em d, a origem da raiz, a partir do centro do tecido cotiledonar. Escala $=1 \mathrm{~cm}$.

Figure 2. Fragmented Eugenia dysenterica DC. (cagaita) seeds germinating. a. two parts of the same seed, each producing a normal seedling. b-d. production of a seedling from root tissues. Note, in $\mathrm{d}$, the root origin, from the center of the cotyledon tissue. Scale $=1 \mathrm{~cm}$. 
resultado da fertilização, o que, provavelmente, confere um alto valor adaptativo (Delgado 2010). E no trabalho de Delgado (2010) não foram utilizadas substâncias exógenas com ação reguladora de crescimento para a obtenção dos novos embriões, demonstrando que apenas a ação mecânica do fracionamento pode estimular a desdiferenciação dos tecidos.

O primeiro trabalho a relatar essa capacidade em sementes de Eugenia foi de Anjos \& Ferraz (1999). Em observações preliminares, os autores constataram que as sementes de E. stipitata eram resistentes a injúrias mecânicas, como cortes. Os autores então testaram esta capacidade cortando as sementes transversalmente ao meio, sendo que uma metade continha a zona meristemática e a outra não, e colocando as duas metades para germinar, lado-a-lado, com a superfície do corte voltada para baixo. Também realizaram cortes de $1 \mathrm{~mm}$ nas sementes, removendo apenas sua zona meristemática. Os resultados demostraram que, de fato, essas sementes possuíam uma grande resistência aos danos físicos. Daquelas cortadas ao meio, $89 \%$ das metades que continham a zona meristemática germinaram, e, surpreendentemente, também houve a formação de plântulas em $20 \%$ das metades opostas à zona meristemática, que os autores chamaram de regeneração. As sementes que tiveram sua zona meristemática removida também foram resistentes às injúrias, pois $77 \%$ delas desenvolveram plântulas normais (Anjos \& Ferraz 1999).

Poucos anos depois, Silva et al. (2003) realizaram diversos tipos de cortes em sementes de E. pyriformis e observaram que esta espécie também possuía uma alta capacidade regenerativa e de resistência aos danos mecânicos. As sementes foram fracionadas de sete formas diferentes, obtendo-se duas, quatro ou até oito partes. Os autores observaram que o corte em um plano longitudinal foi o mais eficiente e que mesmo frações que representavam apenas $1 / 4$ da semente conseguiam germinar e produzir plântulas normais em altas porcentagens, especialmente aquelas frações que continham parte da zona meristemática. Até mesmo aquelas sementes que foram fracionadas em oito partes mantiveram a capacidade de germinar em pelo menos uma das frações.

A capacidade foi então comprovada em mais seis espécies do gênero, sendo três domesticadas (Eugenia involucrata, $E$. uniflora e E. brasiliensis) e três não domesticadas (Eugenia cerasiflora, Eugenia umbelliflora e Eugenia pruinosa), todas mostrando, em maior ou menor grau, a habilidade de germinar mesmo quando parte de sua massa foi removida (Silva et al. 2003, Delgado et al. 2010). A partir daí a capacidade regenerativa passou a ser estudada sob o ponto de vista de uma possível estratégia reprodutiva, uma vez que as reservas nutricionais não são desperdiçadas com germinações simultâneas, mas poupadas para situações de necessidade, como a predação por algum animal, podendo ter contribuído para a grande representatividade do gênero nas florestas brasileiras (Delgado et al. 2010). De fato, ainda que as sementes sejam dispersas imaturas ou até já em germinação, durante um longo período a capacidade regenerativa está presente (Teixeira \& Barbedo 2012).

A ideia de que fragmentos de uma semente monoembriônica sejam capazes de germinar e gerar novas plântulas já é bastante interessante do ponto de vista biológico. Contudo, há ainda outros aspectos interessantes: tendo em vista que essas sementes são sensíveis à dessecação e dispersas com elevado teor de água (ao contrário das sementes tolerantes à dessecação, ou seja, as ortodoxas), elas não conseguem passar por longos períodos no solo aguardando condições favoráveis para germinar, então estão sempre em processo de germinação ou de deterioração (Delgado \& Barbedo 2007, Barbedo et al. 2013, Barbedo 2018). Ainda assim, é possível que essas adversidades ambientais sejam superadas de outra forma pelas sementes recalcitrantes de Eugenia. Se a primeira raiz não encontra um ambiente favorável e acaba secando e morrendo, uma nova germinação começa, e as reservas internas são suficientes para o desenvolvimento de uma nova plântula. Este ciclo poderia se repetir sucessivamente até que uma das plântulas encontrasse condições adequadas e conseguisse se desenvolver sem precisar mais das reservas da semente (Delgado et al. 2010). E a capacidade regenerativa de suas raízes e plântulas já foi demonstrada em sementes de Eugenia candolleana, E. involucrata e E. brasiliensis, que conseguiram produzir plântulas normais por três e quatro vezes consecutivas, a partir da mesma semente (Alonso et al. 2019, Alonso \& Barbedo 2020).

Formar novas raízes e plântulas também pode ter outras vantagens, além da ecológica. Do ponto de vista agronômico, por exemplo, o fracionamento das sementes dessas espécies tem o potencial de ampliar a produção de mudas a partir de uma única semente (figura 3), dado que as espécies de Eugenia têm despertado cada vez mais interesse econômico e que suas mudas são de difícil obtenção (Silva et al. 2003). Contudo, há fatores importantes a serem considerados para a eficiência desse processo, como o número de sementes por fruto e o tamanho das sementes, entre outros. Um maior número de sementes por fruto resulta em sementes menores, e a massa das sementes parece afetar diretamente sua capacidade regenerativa após o fracionamento (Silva et al. 2003). Quando o fruto possui duas sementes, estas são menores do que aquelas provenientes de frutos com uma única semente, principalmente no que diz respeito ao comprimento e à espessura. No entanto, o tamanho das sementes tem maior influência sobre a regeneração do que a quantidade de sementes por fruto (Prataviera et al. 2015). Isso pode ser explicado pela redução na quantidade de reservas como consequência da fragmentação das sementes, o que, nas sementes pequenas, pode limitar o crescimento de raízes, plântulas e brotações (Silva et al. 2003, Teixeira \& Barbedo 2012).

Além disso, é provável que as sementes de Eugenia possuam um refinado sistema de autocontrole da germinação, 


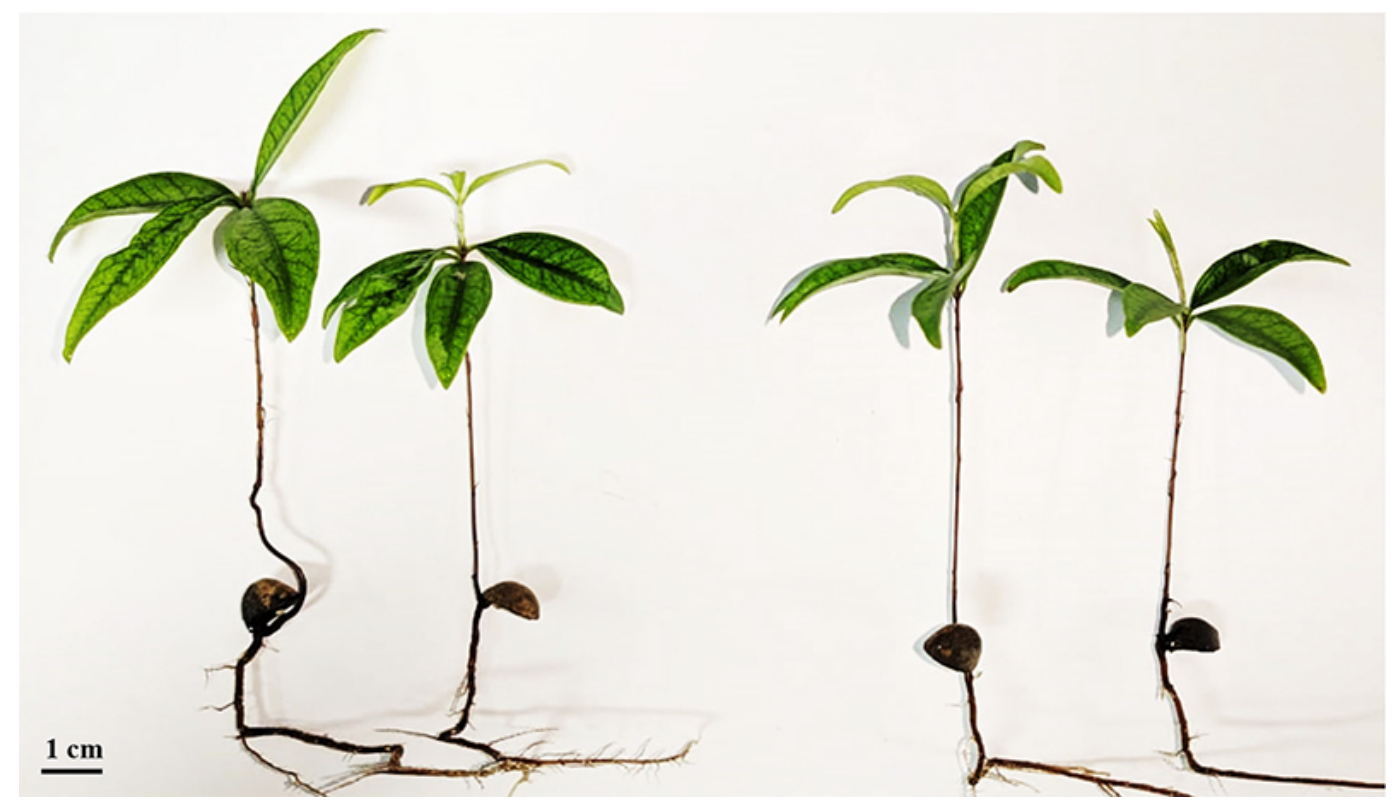

Figura 3. Duas sementes de Eugenia brasiliensis Lam. fracionadas longitudinalmente ao meio, com suas frações produzindo plântulas normais.

Figure 3. Two seeds of Eugenia brasiliensis Lam. cut longitudinally in two parts, each part producing its normal seedling.

pois parece haver um impedimento da produção de mais de uma raiz por vez. E o estímulo da lesão parece ser necessário para que tecidos cotiledonares sejam direcionados à formação de uma nova raiz (que se inicia na bainha dos feixes vasculares), pois em sementes intactas, ou seja, aquelas sementes que não foram submetidas a cortes, raramente ocorre mais de uma germinação (Delgado 2010). Além disso, quando fracionadas, cada fração produz apenas uma nova raiz e uma nova parte aérea, sugerindo a atuação de mecanismos de autocontrole da germinação, responsáveis por evitar múltiplas germinações (Amador \& Barbedo 2015).

Acredita-se, portanto, que estas sementes produzam substâncias estimulantes e inibidoras da germinação, e que a resultante do balanço entre elas direcione os processos para a produção ou não de novas plântulas. Um balanço entre essas substâncias, a favor da inibidora, deve manter ativo apenas um processo germinativo, até que a interrupção no seu transporte (causada pelo fracionamento) permita a produção de uma nova raiz e, consequentemente, uma nova plântula (Delgado \& Barbedo 2011, Amador \& Barbedo 2011, Amador \& Barbedo 2015). Rizzini (1970) verificou que sementes de E. dysenterica possuem substâncias inibidoras da germinação e que esse potencial inibidor aumenta quando o embrião começa a germinar. Delgado $\&$ Barbedo (2011) também demonstraram que extratos de sementes germinantes de E. uniflora apresentam potencial inibidor da germinação e do desenvolvimento inicial das plântulas de alface e feijão.

O início da germinação parece, portanto, iniciar a produção de inibidores de novas germinações nessas sementes. Amador \& Barbedo $(2011,2015)$ demonstraram que em E. pyriformis, E. uniflora e E. brasiliensis o desenvolvimento de uma raiz ou plântula promove processos de inibição do desenvolvimento de novas raízes na mesma semente. Demonstraram, ainda, que a produção de compostos inibidores deve ser contínua, cumulativa e oriunda da região na qual há crescimento da plântula, visto que, em sementes germinantes, nas quais a plântula estava há mais tempo ligada ao cotilédone, a porcentagem de germinação foi menor do que nas não germinantes. Portanto, suspeitase que o desenvolvimento de uma segunda raiz em uma mesma semente dessas espécies é dependente do bloqueio de substâncias ou de processos de inibição que se iniciam quando a primeira germinação ocorre.

Mas é preciso considerar a possibilidade de que as sementes fracionadas de Eugenia estejam sob influência dos dois processos, de indução e de inibição, com balanço ora favorável ao desenvolvimento de novas raízes e plântulas, ora desfavorável. Assim, nas sementes inteiras, a formação de uma única raiz pode ser decorrente da falta de estímulo à regeneração ou de um balanço favorável à inibição. Nas fracionadas, parece evidente que o estímulo à regeneração ocorre e que, quando a germinação se inicia, também se iniciam processos de inibição da regeneração de novas raízes e plântulas. Além disso, o corte das sementes de Eugenia é seguido pelo rápido escurecimento da face cortada exposta ao ar (figura 4), indicando que intensos processos oxidativos estão ocorrendo no local da lesão (Anjos \& Ferraz 1999).

Alguns trabalhos já sugeriram, ainda que de maneira indireta, que a germinação de sementes de Eugenia pode estar intimamente relacionada ao oxigênio (além do metabolismo respiratório). De fato, espécies reativas de oxigênio têm, 

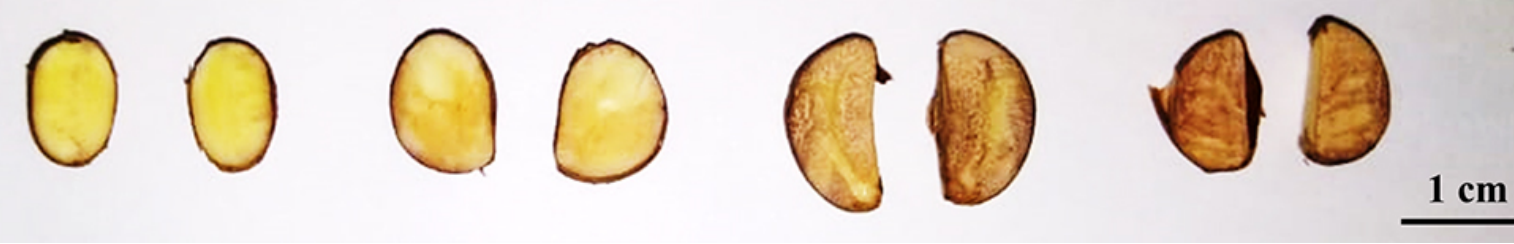

Figura 4. Sementes de Eugenia involucrata DC. fracionadas ao meio, evidenciando, da esquerda para a direita, o escurecimento das faces expostas ao ar.

Figure 4. Eugenia involucrata DC. seeds fractioned in half, showing, from left to right, the darkening of the faces exposed to the air.

entre outras propriedades, a capacidade de induzir processos biológicos e vêm sendo apontadas como peças-chave no processo germinativo de muitas espécies, podendo, portanto, estar relacionadas à indução da formação de novas raízes e plântulas em sementes fracionadas de Eugenia.

\section{Espécies reativas de oxigênio (EROs)}

O oxigênio é um elemento central na vida das sementes, como em todos os eucariontes, e desempenha diversos papéis em sua fisiologia e desenvolvimento. Ainda que algumas delas consigam sobreviver por períodos relativamente longos sob baixas concentrações de oxigênio, sua total ausência é letal para a maioria das espécies, com raras exceções (Hendry 1993). Além da oxidação de compostos envolvida na formação de nutrientes e de moléculas energéticas para o desenvolvimento embrionário, a formação de EROs também está intimamente relacionada a vários aspectos fisiológicos das sementes (Bailly 2004).

De maneira a compreender os possíveis papéis desempenhados por esta molécula nos seres vivos, principalmente nas sementes, primeiramente precisamos compreendê-la em sua estrutura química. Os elétrons envolvidos nas ligações químicas são os elétrons de valência, que para a maioria dos átomos são aqueles que ocupam a camada mais externa. Os átomos costumam ganhar, perder ou compartilhas elétrons a fim de atingir o mesmo número de elétrons que o gás nobre mais próximo a eles na tabela periódica (Brown et al. 2012). Os gases nobres têm arranjos de elétrons muito estáveis e, como todos eles (com exceção do hélio) têm oito elétrons de valência, muitos átomos que sofrem reações também terminam em oito elétrons de valência. Esse padrão de reação é conhecido como "a regra do octeto" (Brown et al. 2012).

A molécula de oxigênio contém um par de elétrons nãopareados em seu orbital mais externo, formando um estado conhecido como tripleto. Esse par de elétrons tem o mesmo giro, ou seja, o mesmo número quântico de rotação (figura 5), e para que o $\mathrm{O}_{2}$ consiga oxidar outro átomo ou molécula, aceitando um par de elétrons, ambos os elétrons adquiridos também precisam ter uma rotação paralela (Green \& Hill 1984). E, uma vez que a maioria das moléculas biológicas tem rotações opostas (ou seja, antiparalelas), isso torna o oxigênio molecular pouco reativo, pois o limita a uma reação de transferência de elétrons por vez, restringindo sua capacidade oxidativa (Cadenas 1989).

Ainda assim, quando um átomo ou molécula possui elétrons não-pareados, a tendência é que eles busquem rapidamente a estabilidade, ao preencher ou esvaziar totalmente seus orbitais através da perda ou ganho de elétrons. Sucessivas reduções do oxigênio por elétrons produzem espécies intermediárias que são relativamente estáveis, contudo, se um dos dois elétrons não pareados estiver excitado e mudar de rotação, a espécie resultante, denominada oxigênio singleto $\left({ }^{1} \mathrm{O}_{2}\right)$, será um poderoso oxidante, visto que, com rotações em sentidos opostos, os dois elétrons podem reagir rapidamente com outros pares de elétrons, especialmente em ligações duplas (Turrens 2003). Nos organismos fotossintetizantes o oxigênio singleto também pode ser gerado pela foto-excitação da clorofila (Desikan et al. 2005).

Moléculas que contêm um ou mais elétrons nãopareados, capazes de existir de forma independente, são chamadas de radicais livres. Devido à necessidade em parear seus elétrons solitários, um radical livre tende a assimilar elétrons de moléculas vizinhas, o que o torna reativo, possibilitando a formação de novos radicais livres e potencialmente a uma reação de auto-propagação em cadeia (Benson 1990, Halliwell 2006). Os radicais livres mais conhecidos são aqueles associados ao oxigênio, pois são excessivamente produzidos nos seres vivos. O radical ânion superóxido $\left(\mathrm{O}_{2}^{-}\right)$, resultado da redução do oxigênio por um elétron, é o precursor da maioria das EROs. Em pH ácido, este ânion pode ser protonado (i.e., sofrer a adição de um próton $\mathrm{H}^{+}$, resultando em um ácido conjugado), formando o radical per-hidroxila $\left(\mathrm{HO}_{2}{ }^{\circ}\right)$ (Bartosz 1997, Turrens 2003). A dismutação do $\mathrm{O}_{2}^{-}$(i.e., reação química na qual parte da molécula é oxidada e outra reduzida), que pode acontecer de maneira espontânea ou através de uma reação catalisada pela enzima superóxido dismutase, produz o peróxido de hidrogênio $\left(\mathrm{H}_{2} \mathrm{O}_{2}\right)$.

$\mathrm{O}_{2} \mathrm{O}_{2}$ não é um radical livre e o oxigênio singleto não é outra forma de oxigênio, mas por conveniência essas sutilezas foram relevadas e ainda hoje todas as formas de oxigênio parcialmente reduzido (além de sua forma totalmente reduzida e inerte) são referidas como espécies 


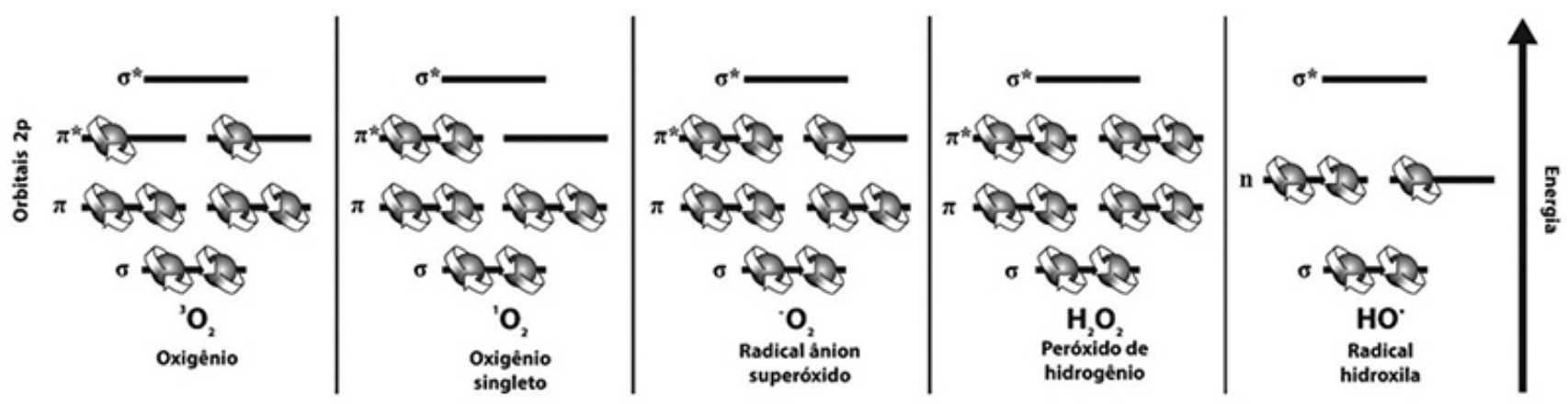

Figura 5. Representação esquemática do diagrama molecular de orbitais para o estado fundamental do oxigênio molecular $\left({ }^{3} \mathrm{O}_{2}\right)$, oxigênio singleto $\left({ }^{1} \mathrm{O}_{2}\right)$, radical ânion superóxido $\left(-\mathrm{O}_{2}\right)$, peróxido de hidrogênio $\left(\mathrm{H}_{2} \mathrm{O}_{2}\right)$ e radical hidroxila $(\mathrm{HO} \bullet)$, baseado na predição da geometria molecular de cada composto. O sentido de giro das esferas representa o spin. Apenas o orbital $2 \mathrm{p}$ e os elétrons de valência estão indicados. $\sigma$ : orbital $\sigma$ ligante. $\sigma^{*}$ : orbital $\sigma$ anti-ligante. $\pi$ : orbital $\pi$ ligante. $\pi^{*}$ : orbital $\pi$ anti-ligante. $n$ : orbital não-ligante. Para maiores detalhes, consultar Barbedo et al. (2018). Reproduzido de Barbedo \& Santos Junior (2018), com autorização.

Figure 5. Schematic representation of the molecular orbital diagram for the ground state of the molecular oxygen $\left({ }^{3} \mathrm{O}_{2}\right)$, singlet oxygen $\left({ }^{1} \mathrm{O}_{2}\right)$, superoxide anion radical $\left({ }^{-} \mathrm{O}_{2}\right)$, hydrogen peroxide $\left(\mathrm{H}_{2} \mathrm{O}_{2}\right)$ and hydroxyl radical $(\mathrm{HO} \bullet)$, based on the prediction of the molecular geometry of each compound. The direction of rotation of the spheres represents the spin. Only the $2 p$ orbital and valence electrons are indicated. $\sigma$ : orbital $\sigma$ ligand. $\sigma^{*}$ : orbital $\sigma$ anti-ligand. $\pi$ : orbital $\pi$ ligand. $\pi^{*}$ : anti-ligand $\pi$ orbital. n: non-binding orbital. For further details, see Barbedo et al. (2018). Duplicated from Barbedo \& Santos Junior (2018), with authorization.

reativas de oxigênio (Hendry 1993). Além disso, o $\mathrm{H}_{2} \mathrm{O}_{2}$ está na via de formação das outras EROs (figura 6), podendo ser completamente reduzido a água ou, se adicionado um elétron e um próton, parcialmente reduzido a radical hidroxila $\left(\mathrm{OH}^{*}\right)$ (Turrens 2003). $\mathrm{O} \mathrm{OH}^{*}$ por sua vez é um dos mais potentes agentes oxidantes da natureza, pois, uma vez formado, possivelmente irá reagir com a primeira molécula orgânica que encontrar (Elstner 1991).

Metais de transição como o ferro geralmente possuem elétrons não pareados, e são excelentes catalisadores de redução do $\mathrm{O}_{2}$, reagindo rapidamente com o peróxido de hidrogênio e produzindo o radical hidroxila (Cadenas 1989). Condições ambientais estressantes podem provocar alterações nos dois processos metabólicos essenciais para o ciclo de vida de vegetais, respiração e fotossíntese, produzindo inevitavelmente EROs em mitocôndrias e nos cloroplastos (Apel \& Hirt 2004). Essa produção ocorre com o desequilíbrio no número de elétrons que são potencialmente transferidos para o oxigênio nas cadeias transportadoras de elétrons dos dois processos (Hendry 1993, Ahmad 2014). E algumas condições são especialmente favoráveis à formação de EROs, como falta de água, alta salinidade, choque térmico, resfriamento, temperaturas elevadas, metais pesados, radiação ultravioleta, alta luminosidade, poluentes atmosféricos, privação de nutrientes, estresse mecânico e ataques por patógenos (Bartosz 1997).

\section{A importância das EROs para as sementes}

As EROs possuem propriedades citotóxicas e, em altas concentrações, podem oxidar descontroladamente proteínas, lipídios e ácidos nucleicos, culminando na ruptura do metabolismo e na destruição das estruturas celulares
(Desikan et al. 2005). De fato, a deterioração das sementes está relacionada, entre outros fatores, à oxidação por EROs, e sua longevidade pode ser aumentada com a eliminação dessas moléculas (Ishibashi et al. 2013). No entanto, as EROs também desempenham um importante papel de sinalização celular nas plantas, controlando processos como crescimento, desenvolvimento, produção hormonal, resposta a estímulos ambientais bióticos e abióticos e morte celular programada (Bailey-Serres \& Mittler 2006).

Da embriogênese à germinação das sementes, as EROs são produzidas continuamente e causam danos ao oxidar diversas moléculas, podendo levar ao estresse oxidativo e resultar na deterioração das sementes (Bailly et al. 2008). Evidentemente, isto também representa um problema para o armazenamento das sementes. A peroxidação lipídica é um dos processos mais citados como resultado do estresse oxidativo e é considerada uma das principais causas de deterioração de sementes ortodoxas oleaginosas, quando os sistemas enzimáticos de defesa não estão atuantes (Bailly 2004). Perda de longevidade devido à peroxidação lipídica também é apontado para sementes recalcitrantes metabolicamente ativas. Entretanto, no caso de algumas espécies, como as de Eugenia, a produção de EROs em situações não favoráveis pode ter levado ao desenvolvimento de mecanismos adaptativos que reaproveitam essas moléculas.

Alguns processos fisiológicos das sementes estão estreitamente ligados à produção de radicais livres, como dessecação e envelhecimento, e são especialmente danosos por levarem ao estresse oxidativo e, consequentemente, a diversos danos celulares (Bailly et al. 2008). Em sementes ortodoxas, que passam por uma grande variação no teor de água e na atividade metabólica ao longo de seu desenvolvimento, a formação de EROs varia consideravelmente (Borisjuk \& 


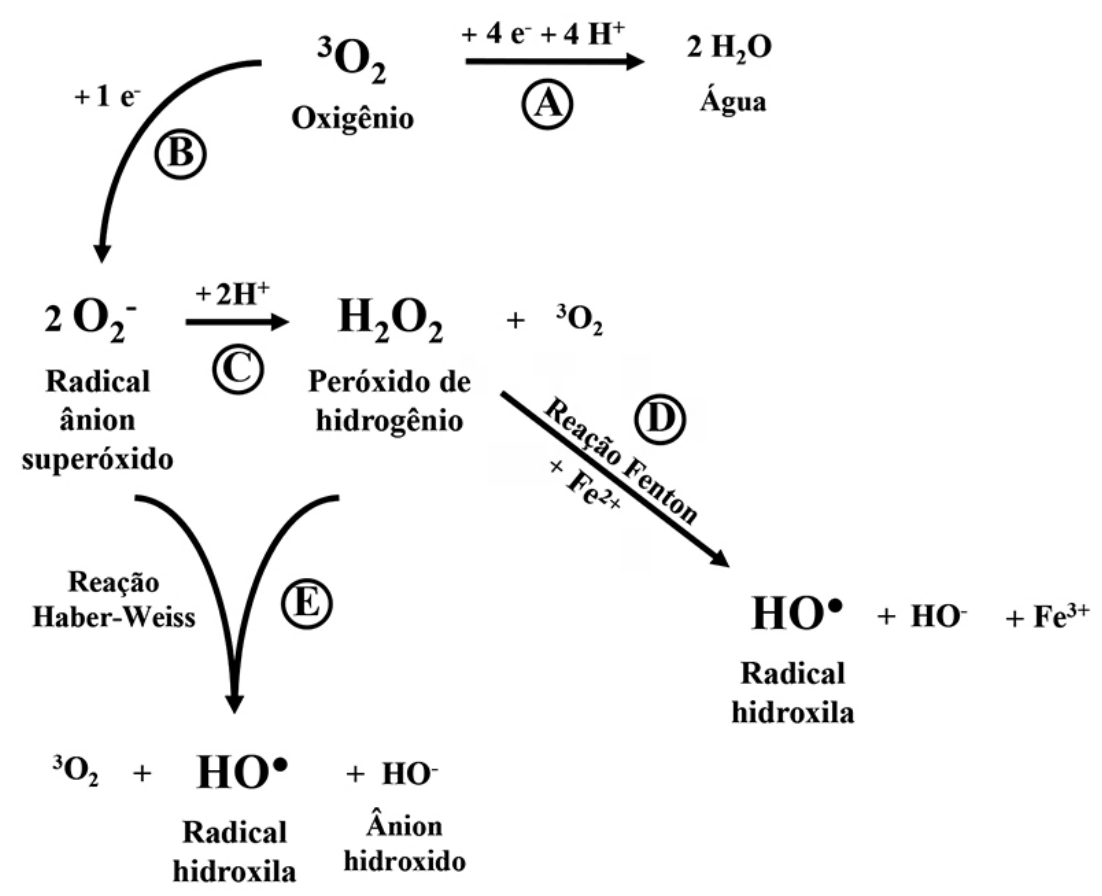

Figura 6. Via univalente da redução do Oxigênio molecular e formação de espécies reativas de oxigênio (EROs). Em A, há a redução completa e estável do oxigênio à água. Em B, um ambiente rico em oxigênio e elétrons livres favorece a formação do radical ânion superóxido, além de promover a geração de peróxido de hidrogênio (em C), que não é um radical livre, mas está na via de formação do radical mais reativo existente, o radical hidroxila (em D e E). Adaptado de Halliwell \& Gutteridge (2007). Reproduzido de Barbedo \& Santos Junior (2018), com autorização.

Figure 6. Univalent reduction pathway of molecular oxygen and formation of reactive oxygen species (ROS). In A, there is a complete and stable reduction of oxygen to water. In $\mathrm{B}$, an environment rich in oxygen and free electrons favors the formation of the superoxide anion radical, in addition to promoting the generation of hydrogen peroxide (in C), which is not a free radical, but it is substrate for the pathway of the most reactive radical in existence, the hydroxyl radical (in D and E). Adapted from Halliwell \& Gutteridge (2007). Duplicated from Barbedo \& Santos Junior (2018), with authorization.

Rolletschek 2009). Nas etapas iniciais do desenvolvimento (embriogênese), o teor de água elevado reflete uma intensa atividade metabólica necessária para as divisões celulares, e se mantem fundamental para permitir o transporte de metabólitos e o acúmulo de reservas no embrião ou em suas estruturas adjacentes durante a etapa de maturação (Marcos Filho 2015). Durante ambas as etapas o gasto energético demanda altas taxas respiratórias, que resultam inevitavelmente na formação de EROs (Huang et al. 2012). Ao final da maturação, sementes ortodoxas passam por uma etapa de secagem e seus mecanismos de tolerância à dessecação em diferentes níveis são evidenciados. Entretanto, a formação de EROs é inevitável, tornando-as dependentes de mecanismos adaptativos, como as moléculas antioxidantes, para evitar o estresse oxidativo e garantir sua sobrevivência (Bailly 2004).

As sementes recalcitrantes, semelhantes aos primeiros estágios de desenvolvimento das ortodoxas, são sensíveis à dessecação, permanecendo úmidas desde sua formação até a germinação, mantendo um alto metabolismo e altas taxas respiratórias durante todo o seu ciclo de vida (Barbedo et al. 2013, Barbedo 2018). Condições ambientais que levem essas sementes a ocasionais perdas de água estão associadas a danos celulares, e vários mecanismos de proteção das estruturas celulares contra a geração de EROs tornam-se progressivamente ineficientes durante a perda de água e posterior reidratação (Bailly et al. 2008). Quando as vias da glicólise e o ciclo do ácido tricarboxílico são prejudicados e as membranas mitocondriais danificadas, as cadeias transportadoras de elétrons podem ser facilmente desviadas para a produção de radicais livres (Benson 1990). As mitocôndrias são, provavelmente, uma das principais fontes de EROs no desenvolvimento ou germinação de sementes (Moller 2001), e aproximadamente 2 a 3\% do oxigênio utilizado leva à produção de superóxido e peróxido de hidrogênio (Chance et al. 1973, Puntarulo et al. 1988). A quantidade de $\mathrm{H}_{2} \mathrm{O}_{2}$ produzida é, portanto, diretamente proporcional à atividade respiratória (Staniek \& Nohl 2000). $\mathrm{E}$, à medida que os produtos tóxicos das reações de radicais livres se acumulam, macromoléculas vão sendo danificadas (Benson 1990).

Além da mitocôndria, cloroplastos também podem ser uma fonte de EROs durante o desenvolvimento das sementes com embriões verdes. Neste caso, a atividade desta organela estaria relacionada à produção de oxigênio nos tecidos mais interiores do embrião, permitindo a formação de ATP em 
regiões em que a restrição de oxigênio afetaria o metabolismo celular (Borisjuk \& Rolletschek 2009). Já os peroxissomos (ou glioxissomos, em sementes oleoginosas) produzem $\mathrm{O}_{2}{ }^{-}$ e $\mathrm{H}_{2} \mathrm{O}_{2}$ e promovem o ciclo do glioxilato, que convertem as reservas lipídicas em açúcares durante os primeiros estágios do desenvolvimento das mudas (El-Maarouf-Bouteau \& Bailly 2008).

As moléculas antioxidativas, que podem ser de natureza enzimática e não-enzimática, estão em concentrações baixas quando comparadas a um substrato oxidável e têm o papel de atrasar ou inibir a oxidação desses substratos (Halliwell \& Gutteridge 2015, Sies 1997). Situações de estresse induzem tanto a formação de EROs, quanto as respostas de proteção, e as células vegetais como um todo, mas principalmente algumas de suas organelas (mitocôndrias, cloroplastos e peroxissomos) contêm um conjunto completo de moléculas de defesa contra o ataque oxidativo, controlando os níveis de EROs. Consequentemente, diversos compostos antioxidantes desempenham papéis fundamentais em vários processos durante a vida das sementes, como a aquisição da tolerância à dessecação, o desenvolvimento, a longevidade das sementes e a conclusão da germinação (Bailly 2004).

A produção de EROs em sementes foi por muito tempo considerada unicamente prejudicial, uma vez que estava quase sempre associada a dois processos especialmente danosos, o envelhecimento e a dessecação, ambos frequentemente levando ao estresse oxidativo (Bailly 2004). Contudo, nos últimos anos, diversos estudos têm demonstrado o papel das EROs na sinalização de processos e sua importância no crescimento e desenvolvimento das plantas. $\mathrm{O} \mathrm{H}_{2} \mathrm{O}_{2}$, por exemplo, tem sido apontado como responsável por diversos processos celulares, como a morte celular programada, a indução de embriogênese somática, repostas a ferimentos etc. (El-Maarouf-Bouteau \& Bailly 2008). Além disso, atualmente já são conhecidas enzimas geradoras de EROs que tornam as células vegetais capazes de ampliar a produção de EROs para fins de sinalização (Bailey-Serres \& Mittler 2006). E, desde que exista um equilíbrio entre sua produção e eliminação, as EROs podem afetar positivamente a germinação e, em particular, atuarem como um sinal positivo para a superação da dormência.

Como moléculas relacionadas à sinalização celular, as EROs interagem com outras moléculas-em especial com os hormônios -, e estão envolvidas com o desenvolvimento das sementes, participando nos processos de crescimento que ocorrem no início da embriogênese e nos mecanismos ligados à protrusão radicular durante a germinação. As EROs também desempenham uma função reguladora na expressão gênica durante o desenvolvimento, a dormência e a germinação das sementes (Bailly 2004), e interferem nas movimentações de cálcio intracelular (Bailly et al. 2008). Também oferecem uma proteção contra agentes patogênicos, sendo diretamente tóxicas aos patógenos ou isolando a região atacada através de morte celular programada (El-Maarouf-Bouteau \& Bailly 2008). Schopfer et al. (2001) sugeriram que a produção de EROs em sementes germinantes de rabanete (Raphanus sativus) representa uma função fisiologicamente ativa para proteger as mudas emergentes contra os ataques de patógenos.

A capacidade de germinação das sementes parece estar relacionada ao acúmulo de $\mathrm{H}_{2} \mathrm{O}_{2}$, uma vez que sementes embebidas não dormentes parecem produzir mais $\mathrm{H}_{2} \mathrm{O}_{2}$ do que sementes embebidas dormentes, sugerindo uma regulação diferencial dos mecanismos de produção e de eliminação de EROs nestes dois tipos de sementes (Oracz et al. 2007, Bailly et al. 2008). Curiosamente, também há um acumulo de $\mathrm{H}_{2} \mathrm{O}_{2}$ durante $\mathrm{o}$ armazenamento de sementes secas, que, além do envelhecimento durante armazenamentos prolongados, pode estar associado à superação de dormência no pós-amadurecimento, condição na qual sementes de algumas espécies, secas e dispersas, só superam a dormência durante o armazenamento em condições secas ou na embebição em baixas temperaturas (Kibinza et al. 2006, Oracz et al. 2007, Bailly et al. 2008).

Após o amadurecimento há um acúmulo progressivo de radicais superóxido e peróxidos de hidrogênio nas células do eixo embrionário. Este acúmulo ocorre simultaneamente com a peroxidação lipídica e a oxidação de proteínas embrionárias específicas. Oracz et al. (2007) incubaram sementes dormentes na presença de metilviologênio (ou paraquat), um herbicida bipiridílico tóxico para as plantas devido à sua propensão a desviar elétrons de cadeias transportadoras de elétrons diretamente para o oxigênio e promover a produção de EROs (Leprince et al. 1993). Os autores verificaram a superação de dormência nestas sementes (Oracz et al. 2007). Por outro lado, a aplicação de antioxidantes parece suprimir de forma significativa a germinação de sementes de várias espécies (Ogawa \& Iwabuchi 2001, Ishibashi \& Iwaya-Inoue 2006). A aplicação de $\mathrm{N}$-acetil-L-cisteína, um precursor da glutationa, inibe a produção de $\mathrm{H}_{2} \mathrm{O}_{2}$ no eixo embrionário após a embebição, diminuindo a germinação de sementes. E seu efeito é potencializado com o aumento da concentração (Ishibashi et al. 2013).

Além disso, é provável que exista uma relação entre as EROs e o ácido abscísico (ABA), inibidor de germinação, ou a giberelina (GA), indutor de germinação. A aplicação de $\mathrm{ABA}$ não só inibe significativamente a germinação como reduz a taxa de $\mathrm{H}_{2} \mathrm{O}_{2}$ em sementes. $\mathrm{E}$ a regulação do conteúdo de $\mathrm{ABA}$ e o aumento de GA sugere uma interação com as EROs (Su et al. 2016). Por exemplo, a produção de $\mathrm{H}_{2} \mathrm{O}_{2}$ pode ser induzida por $\mathrm{GA}$ em células de aleurona, e suprimida por ABA. $\mathrm{O} \mathrm{H}_{2} \mathrm{O}_{2}$ exógeno parece promover a indução de $\alpha$-amilases por GA, enquanto antioxidantes suprimem a indução de $\alpha$-amilases. Portanto, $\mathrm{o}_{2} \mathrm{O}_{2}$, gerado por GA em células de aleurona, prromoveria a produção de $\alpha$-amilase, indicando que o $\mathrm{H}_{2} \mathrm{O}_{2}$ teria papel antagônico à sinalização do ABA (Ishibashi et al. 2012).

Mas a relação entre a função sinalizadora das EROs e as sementes recalcitrantes ainda é pouco explorada. Somente nos últimos anos se demonstrou essa relação como, por exemplo, os trabalhos que mostram o aumento na produção de radicais superóxido em sementes e eixos de sementes 
recalcitrantes com a desidratação, correlacionando com o declínio nas atividades das enzimas antioxidantes (Pukacka \& Ratajczak 2006, Cheng \& Song 2008). Roach et al. (2008) demonstraram que a excisão do eixo embrionário em sementes recalcitrantes de Castanea sativa resultou em um nítido aumento na produção extracelular de EROs, imediatamente antes do alongamento do eixo, sendo o $\mathrm{O}_{2}{ }^{-}$o componente principal dessa explosão oxidativa. Essa produção extracelular de radical superóxido pareceu desempenhar papéis fundamentais na sobrevivência e germinação dessas sementes submetidas a leves secagens (Roach et al. 2010). É possível que a produção do $\mathrm{O}_{2}$ - pelos eixos embrionários em determinadas janelas de tempo pode ser resposta catalisada por enzimas, participando de vias de sinalização que estão relacionadas a mecanismos de defesa ou proteção ao aumento do estresse pela dessecação em sementes recalcitrantes, favorecendo a regeneração e o crescimento dos tecidos (Roach et al. 2010).

Varghese et al. (2011) mostraram que a leve desidratação de eixos embrionários de Trichilia dregeana, acompanhada por altos níveis de $\mathrm{O}_{2}$, estimulou a germinação, como um gatilho bioquímico. Os autores sugerem que a diminuição nos níveis de superóxido após a desidratação para teores de água mais reduzidos poderia ser responsável pelo declínio da germinação nos eixos de Trichilia dregeana parcialmente secos. Curiosamente, Moothoo-Padayachie et al. (2016) também demonstraram que o $\mathrm{O}_{2}{ }^{-}$e $\mathrm{H}_{2} \mathrm{O}_{2}$ desempenham um papel crucial na germinação de Trichilia dregeana e Avicennia marina, além de uma forte correlação positiva entre a captação de água, a taxa de produção de EROs e a germinação máxima dessas sementes. Outra evidência da relação positiva entre a germinação de sementes recalcitrantes de A. marina e T. dregeana e a produção de EROs é que, quando expostas a diphenylene iodonium, um potente inibidor da NADPH oxidase, a respiração não foi bloqueada, mas a germinação foi inibida. Além disso, a germinação de $A$. marina também foi comprometida com a exposição a dimethylthiourea, um eliminador de $\mathrm{H}_{2} \mathrm{O}_{2}$ (Moothoo-Padayachie et al. 2016).

Finalmente, diferente das sementes ortodoxas, nas quais os níveis de ascorbato tornam-se mínimos ou ausentes ao final da maturação, em sementes recalcitrantes os níveis do antioxidante mantêm-se elevados após a dispersão (Tommasi et al. 1999). Tendo em vista que o metabolismo dessas sementes se mantém alto ao longo de todo o processo desenvolvimento-germinação, levando à constante formação de EROs, é provável que um eficiente sistema antioxidativo seja necessário para controlar os processos oxidativos a níveis benéficos.

\section{O papel das EROs em sementes de Eugenia}

Ainda que os trabalhos que buscam entender os efeitos das EROs em sementes recalcitrantes sejam poucos e que os processos envolvidos na indução de novas raízes ou plântulas em sementes fracionadas de Eugenia não estejam esclarecidos, algumas evidências indiretas apontam para a possível interação entre a produção de EROs e a germinação e regeneração dessas sementes. E essa relação já foi estudada e confirmada por Amador (2015). Segundo a autora, uma vez que as lesões nessas sementes expõem partes internas ao ar, induzindo a formação de EROs e desencadeando processos oxidativos, é possível que as EROs estejam associadas à indução de novas raízes e plântulas em sementes de Eugenia, e o rápido escurecimento da superfície lesionada exposta ao ar pode ser resultado da ação da polifenoloxidase, que oxida os compostos fenólicos e produz substâncias escuras (Amador 2015).

O trabalho de Amador (2015) buscou verificar se sementes fracionadas de Eugenia submetidas a aplicações exógenas de ácido ascórbico (AA) e polivinilpirrolidona (PVP), mantinham sua capacidade de produzir raízes. O AA é a forma não ionizada do ascorbato, que, por sua vez, é a forma biologicamente ativa da vitamina $\mathrm{C}$, considerada uma das principais substâncias fitoquímicas com propriedades antioxidantes, e é extremamente importante na intercepção dos radicais livres oriundos de processos oxidativos (Kitts 1997). Já o PVP é capaz de adsorver substâncias fenólicas e seus produtos da oxidação (Teixeira 2004). Sementes e frações de sementes de E. cerasiflora colocadas para germinar em soluções de PVP demonstraram uma evidente inibição no desenvolvimento das plântulas (Amador 2015). A aplicação do PVP também suprimiu substancialmente a formação de raízes em sementes de $E$. brasiliensis, que caiu de $70 \%$ para menos de $20 \%$ (Amador 2015). Sementes inteiras e fracionadas de $E$. brasiliensis imersas nas soluções de AA e PVP também demonstraram que a formação de novas raízes depende de processos oxidativos, uma vez que estes causaram grande redução na germinação (Amador 2015).

À princípio, a aplicação do AA foi letal para as sementes, sugerindo que as concentrações utilizadas tenham sido muito elevadas. Mas ajustes nas concentrações evidenciaram os efeitos da oxidação sobre a produção de raízes em sementes de E. uniflora, pois a aplicação de AA foi diminuindo a porcentagem de germinação de acordo com o aumento de sua concentração. E, ao inibir os processos oxidativos em sementes de Eugenia, principalmente E. uniflora, que passaram por algum tipo de lesão (como o fracionamento), é provável que a sinalização dos hormônios envolvidos na germinação também tenha sido inibida, uma vez que sementes fracionadas e tratadas com $\mathrm{AA}$ não tiveram sua capacidade regenerativa destacada (Amador 2015).

Existem outras evidências indiretas da influência das EROs no processo germinativo de sementes de Eugenia como, por exemplo, a existência de mecanismos de autorregulação que controlam a germinação nessas sementes. Quando sementes não-germinadas são apenas físsuradas (incisão parcial), os valores de formação de raízes são superiores a 1,0, mas em sementes germinadas isso não 
acontece, evidenciando a existência de processos de inibição do desenvolvimento de novas raízes e, ao mesmo tempo, o estímulo causado pelo corte (Amador \& Barbedo 2011). De fato, sementes de E. uniflora que foram fracionadas parcialmente apresentaram taxas de germinação maiores do que as sementes intactas (i.e., grupo controle que não passou por nenhum tipo de corte), sugerindo que a fissura tenha induzido a diferenciação de tecidos que produzem raízes e mudas, uma vez que as sementes intactas apenas emitiriam uma raiz primária (Amador \& Barbedo 2015).

Esse autocontrole da germinação mostra-se intimamente relacionado às EROs, pois ao analisar os materiais vegetais provenientes de sementes de Eugenia, o composto majoritário encontrado, que parece estar relacionado à inibição de novas raízes, foi o ácido elágico, que tem recebido muita atenção por seu potencial nutricional e farmacológico, em especial sua atividade antioxidante e antiviral (Amador 2015). Além disso, o ácido elágico é considerado um antioxidante fenólico que auxilia a resposta antioxidante da célula, atuando como modulador redox na eliminação de radicais livres (Vattem \& Shetty 2005). O segundo composto em evidência foi o ácido gálico (Amador 2015), que também exibe uma ampla variedade de funções biológicas, em especial sua atividade antioxidante primária (Fiuza et al. 2004).

Essas análises indicam que as substâncias envolvidas na inibição de uma segunda raiz em sementes de Eugenia podem ser o ácido elágico e o ácido gálico, pois esses compostos atuam na atividade enzimática que disponibiliza energia para iniciar a germinação (Amador 2015). Tanto o ácido gálico quanto o elágico são conhecidos na literatura como inibidores seletivos da atividade da $\alpha$-glucosidase. A $\alpha$-glucosidase converte o amido em maltose, sendo muito importante para o início do processo germinativo, e sua inibição poderia inibir novas germinações. Além disso, os flavonoides, que são fenóis como os ácidos gálico e elágico, são conhecidos como poderosos antioxidantes, e parecem atuar primeiramente como inibidores da germinação e do sistema de transferência de energia dentro da célula (Amador 2015 e referências contidas).

Finalmente, ainda que essas sementes demonstrem a capacidade de germinar e se regenerar já nos primeiros estágios de desenvolvimento (Teixeira \& Barbedo 2012), não há registros de germinação dessas sementes dentro do próprio fruto, como acontece com sementes de outras espécies recalcitrantes e germináveis ainda imaturas como as de Inga vera Wild. subsp. affinis (DC.) T.D. Pennington (Bonjovani \& Barbedo 2014). Logo, é provável que os inibidores também estejam presentes nos frutos, impedindo a germinação dentro destes. Extratos da polpa de frutos de Eugenia sempre apresentaram ácido elágico em sua composição, e demonstram que antioxidantes são responsáveis pela inibição da germinação enquanto a semente ainda está no fruto (Amador 2015). A polpa de E. brasiliensis apresenta capacidade inibitória contra alguns microrganismos, como Pseudomonas aeruginosa,
Staphylococcus aureus e Bacillus cereus devido à presença de compostos fenólicos, que contribuem para a capacidade antioxidante desse fruto (Zola et al. 2019). A polpa de frutos de E. uniflora também é rica em diversos compostos com atividade antioxidante, como licopeno, $\beta$-criptoxantina e $\beta$-caroteno, compostos fenólicos e antocianinas (Bagerri et al. 2011). Diversos trabalhos também revelam o potencial antioxidante da polpa de frutos de Eugenia, em E. stipitata (Garzon et al. 2012, Neri-Numa et al. 2013), E. uniflora (Celli et al. 2011), E. involucrata (Nicácio et al. 2017), E. jambolana (Sultana et al. 2007).

Portanto, se considerarmos que as sementes de Eugenia já estão prontas para germinar logo no início de seu desenvolvimento, uma vez que possuem quantidade de água suficiente e estão em um continuum de maturaçãogerminação, com o metabolismo completamente ativo em todas as etapas (Barbedo 2018), e que as EROs desempenham papel fundamental na sua germinação, a planta-mãe deve controlar essa germinação de alguma forma. Este controle pode ser desempenhado pelas substâncias antioxidativas contidas nos frutos, resultando em uma complexa relação entre as EROs e os hormônios relacionados à germinação. Quando o fruto é disperso e a semente extraída, a redução do contato da semente com os antioxidantes da polpa deve permitir um aumento no acúmulo de EROs decorrente da própria respiração, dando rapidamente início à germinação, uma vez que a água disponível no ambiente não representa um fator limitante para essas sementes, pois sua quantidade interna é suficiente para permitir o início do próprio processo germinativo.

Em síntese, as EROs e os antioxidantes, que desempenham diversos papéis importantes sobre a vida das sementes, parecem atuar com a mesma intensidade na fisiologia de sementes de Eugenia, ainda que neste caso essas relações sejam pouco conhecidas. Estudos com sementes ortodoxas durante o início do desenvolvimento (embriogênese) mostram que o conteúdo de $\mathrm{H}_{2} \mathrm{O}_{2}$ é elevado nesta etapa, provavelmente devido a maior umidade dos tecidos, que mantêm as sementes metabolicamente ativas durante esse período. Quando colhidas prematuramente, sem que os sistemas antioxidantes ainda estejam totalmente funcionais, as sementes imaturas podem inclusive apresentar elevadas taxas de oxidação, causando rápida deterioração (Blokhina et al. 2003, Lamarca \& Barbedo 2012, Araujo \& Barbedo 2017). Quando essas sementes entram na etapa de dessecação, o conteúdo de peróxido de hidrogênio diminuí e só volta a aumentar durante a embebição, resultando na reativação do metabolismo (Bailly et al. 2008). Tendo em vista que as sementes de Eugenia são recalcitrantes e mantêm altos níveis de umidade durante todo o seu desenvolvimento, é provável que os níveis de $\mathrm{H}_{2} \mathrm{O}_{2}$ também permaneçam elevados.

Outros trabalhos têm relacionado a produção de EROs, principalmente de $\mathrm{H}_{2} \mathrm{O}_{2}$, com a carbonilação de proteínas específicas nos eixos dormentes e a consequente quebra da dormência (Oracz et al. 2007). Tratamentos com $\mathrm{H}_{2} \mathrm{O}_{2}$ 
exógeno ou methylviologen demonstraram a indução da germinação em sementes dormentes de diversas espécies, como cevada (Fontaine et al. 1994), arroz (Naredo et al. 1998), Zinnia elegans (Ogawa \& Iwabuchi 2001), maçã (Bogatek et al. 2003) e girassol (Oracz et al. 2007, 2009). A aplicação de EROs ou compostos geradores de EROs favoreceu a germinação de sementes de Hedysarum scoparium, que apresentavam apenas $21 \%$ de germinação em condições normais e, quando submetidas a tratamentos com $50 \mathrm{mM}$ de $\mathrm{H}_{2} \mathrm{O}_{2}$ ou $1 \mathrm{mM}$ de methylviologen, tiveram sua taxa de germinação elevada para $79 \%$ e $84 \%$, respectivamente ( $\mathrm{Su}$ et al. 2016). Segundo os autores, a germinação de sementes de $H$. scoparium está claramente associada ao acúmulo de ânions superóxido e peróxidos de hidrogênio nos eixos embrionários.

As EROs são apontadas como moléculas que atuam como mensageiras celulares, podendo estar ligadas não só a sinalizações para a liberação da dormência, mas também favorecendo a germinação propriamente dita (Bailly 2004). A oxidação de proteínas de reserva pode estar relacionada ao estímulo da germinação exercido pelas EROs, pois em embriões de girassol, a produção de $\mathrm{H}_{2} \mathrm{O}_{2}$ e a carbonilação de proteínas foram desencadeadas e acompanhadas de um alto estímulo da germinação, semelhante àquele induzido por cianeto de hidrogênio (Oracz et al. 2009).

Nas sementes de Eugenia tratadas com AA ou PVP, estes antioxidantes também podem ter interferido na síntese de etileno, que pode não estar diretamente relacionado à germinação dessas sementes, mas à produção de novas raízes em sementes fracionadas, como uma resposta ao estresse e à produção de EROs no local da lesão. De fato, a produção de etileno em resposta à geração de EROs está ligada à germinação de sementes, e a primeira resposta ao etileno durante a germinação é o estímulo à expansão radicular (Kucera et al. 2005, Ishibashi et al. 2013).

$\mathrm{O}$ tratamento com $\mathrm{N}$-acetylcysteine, que também atua como um antioxidante, induz a expressão de genes que inibem a sinalização de etileno (Ishibashi et al. 2013), enquanto tratamentos com $\mathrm{H}_{2} \mathrm{O}_{2}$ parecem aumentar significativamente a produção deste hormônio, o qual, entre outros efeitos, está relacionado ao crescimento e ao desenvolvimento das plantas, incluindo a quebra da dormência de sementes de algumas espécies, a germinação e o aumento na emergência da radícula em condições desfavoráveis (Buchanan et al. 2015). Além disso, a síntese de etileno também é elevada pelas condições de estresse, inclusive de ferimentos mecânicos, e está envolvida no início das respostas ao estresse, como na regeneração de lesões (Taiz \& Zeiger 2013).

O uso de EROs como moléculas de sinalização nas plantas sugere uma adaptação no curso evolutivo dos mecanismos antioxidativos, permitindo às células o controle da toxicidade e o uso dessas moléculas como transdutoras de sinais (Bailey-Serres \& Mittler 2006). Estudos sobre os efeitos das EROs em sementes têm procurado esclarecer a diversidade dos papéis desempenhados por esses compostos.
Além dessa dificuldade, também há a necessidade de estudos que procurem documentar adequadamente as prováveis fontes desses compostos, bem como identificar seus alvos celulares e determinar se eles são uma conexão entre sinais ambientais e sinalização hormonal (Bailly et al. 2008).

Sensores de EROs podem ser ativados para induzir cascatas de sinalização que afetam a expressão gênica nas plantas. A transdução de sinal é um processo de transmissão de informações da parte externa da célula para vários elementos internos, resultando em mudanças no transcriptoma nuclear (Ahmad et al. 2008). Uma grande rede de genes é necessária para controlar a toxicidade de EROs e ao mesmo tempo utilizá-las na sinalização celular. Diferentes sinais, internos ou externos às plantas, alimentam a cadeia de sinalização de EROs e perturbam seu equilíbrio de maneiras específicas. Os níveis desequilibrados de EROs são percebidos por diferentes proteínas, enzimas ou receptores, que modulam caminhos de desenvolvimento, de defesa ou metabólicos (Mittler et al. 2004).

A interação entre os caminhos de produção e de eliminação das EROs nas células determina a intensidade, a duração e a localização dos seus sinais. A rede de genes das EROs modula o nível estável destas moléculas nas células para fim de sinalização, bem como para proteção contra danos oxidativos (Mittler et al. 2004). A quantidade e a natureza da ERO determinam o tipo de resposta. O radical superóxido e o peróxido de hidrogênio parecem desempenhar um papel chave como moléculas transdutoras de sinal, pois podem induzir genes diferentes, em combinação ou separadamente, dando mais flexibilidade à função de sinalização das EROs (Breusegem et al. 2001, Mittler et al. 2004).

Níveis inofensivos de EROs podem aclimatar as plantas a condições de estresse biótico ou abiótico, bem como reduzir seu crescimento como uma resposta adaptativa. No entanto, os mecanismos moleculares de adaptação ainda são mal compreendidos e as vias de sinalização envolvidas permanecem incertas. Novos estudos moleculares e fisiológicos devem ajudar a elucidar questões quanto a posição de sinais das EROs em cascatas de transdução e melhorar nossa compreensão sobre sua percepção e tradução em respostas celulares (Breusegem et al. 2001).

\section{Considerações finais}

Embora nos últimos anos muitos trabalhos tenham sido publicados sobre o papel das EROs nas sementes, a grande maioria se restringe às ortodoxas, com pouca ou nenhuma atenção quanto ao desenvolvimento de sementes recalcitrantes. Entretanto, tem sido revelado que, como em sementes ortodoxas, as EROs também desempenham um papel crucial no processo germinativo das recalcitrantes (Roach et al. 2010, Varghese et al. 2011, MoothooPadayachie et al. 2016). E o universo fisiológico das 
sementes recalcitrantes exibe uma miríade de adaptações com as EROs certamente relacionadas a muitas delas - que as tornam extremamente vigorosas e competitivas em seus ambientes naturais embora, de forma colateral, as tornem inviáveis para o armazenamento.

As sementes de Eugenia apresentam estratégias muito interessantes para garantir a propagação de suas espécies, especialmente por não se enquadrarem nos clássicos modelos de formação de bancos de sementes no solo. Nesses modelos, a tolerância à dessecação que leva as sementes a um estado de quiescência, principalmente quando associada à dormência, sempre foi considerado como vantajosa para a multiplicação das espécies no tempo e no espaço. Isso porque, estando secas e dependendo de água para germinar, as sementes dispersas podem ser levadas pelo vento, por animais e outros veículos a lugares distantes da planta que as originou, colonizando novas áreas tão logo as condições do meio permitissem, especialmente o fornecimento de água. Quando tais sementes são dormentes, podem esparramar a germinação também no tempo, pois a dormência não é uniformemente conferida às sementes de uma mesma safra, umas germinando em semanas e outras em anos ou décadas (Barbedo 2018).

Sementes sensíveis à dessecação, como as de Eugenia, são dispersas com elevado conteúdo de água e não podem ser secas até os níveis tolerados pelas sementes ortodoxas (Delgado \& Barbedo 2007). A formação de banco de sementes no solo, portanto, não seria a ferramenta mais apropriada para a espécie colonizar diferentes épocas ou espaços. Contudo, por essa capacidade em produzir reservas em quantidade muito superior à necessária para uma germinação e estabelecimento da planta, associada à capacidade de regenerar sucessivas raízes e/ou plântulas sempre que uma é perdida (Alonso \& Barbedo 2020), demonstra que a tolerância à dessecação e a dormência podem ser substituídos por outros mecanismos de manutenção de diásporos em condições de germinar em diferentes épocas e locais. As sementes de Eugenia sp. parecem ter sido selecionadas sob outro padrão de investimento ecológico evolutivo, dispensando o elevado custo da tolerância à dessecação em prol do investimento na capacidade de produzir diversas plantas a partir de uma única semente, bem como no controle da germinação, ora na direção do estímulo, ora em sua inibição. Este controle parece ter relação íntima com os processos de oxidação e de formação de substâncias capazes de, rapidamente, serem distribuídas por todos os tecidos onipotentes e inibirem novas diferenciações de embriões sempre que uma germinação se inicia. Após duas décadas das primeiras descobertas desses sistemas, ainda se está muitos distante da compreensão de todos os processos envolvidos. Muito se avançou nestas décadas, mas há, ainda, muito trabalho pela frente.

\section{Literatura citada}

Abe, L.T., Lajolo, F.M. \& Genovese, M.I. 2012. Potential dietary sources of ellagic acid and other antioxidants among fruits consumed in Brazil: jabuticaba (Myrciaria jaboticaba (Vell.) Berg). Journal of the Science of Food and Agriculture 92: 1679-1687.

Ahmad, P. 2014. Oxidative damage to plants: Antioxidant networks and signaling. San Diego, Elsevier.

Ahmad, P., Sarwat, M. \& Sharma, S. 2008. Reactive oxygen species, antioxidants and signaling in plants. Journal of Plant Biology 5: 167-173.

Alonso, C.R. \& Barbedo, C.J. 2020. Germinações sucessivas em sementes de Eugenia spp. Hoehnea 47: e412019.

Alonso, C.R., Asperti, L.M., Guardia, M.C. \& Barbedo, C.J. 2019. Cutting and regeneration of roots and seedlings from seeds of Eugenia candolleana DC. at different maturity stages. Journal of Seed Sciences 41: 160-167.

Amador, T.S. 2015. Estudos fitoquímicos e fisiológicos dos processos de indução e inibição da regeneração de plântulas de sementes de Eugenia. Tese de Doutorado. Universidade Estadual Paulista, Botucatu.

Amador, T.S. \& Barbedo, C.J. 2011. Potencial de inibição da regeneração de raízes e plântulas em sementes germinantes de Eugenia pyriformis. Pesquisa Agropecuária Brasileira 46: 814-821.

Amador, T.S. \& Barbedo, C.J. 2015. Germination inhibits the growth of new roots and seedlings in Eugenia unifora and Eugenia brasiliensis. Journal of Seed Science 37: 241-247.

Andrade, R.N.B. \& Ferreira, A.G. 2000. Germinação e armazenamento de sementes de uvaia (Eugenia pyriformis Camb.) - Myrtaceae. Revista Brasileira de Sementes 22: 118-125.

Anjos, A.M.G. \& Ferraz, I.D.K. 1999. Morfologia, germinação e teor de água das sementes de araçá-boi (Eugenia stipitata ssp. sororia). Acta Amazonica 29: 337-348.

Apel, K. \& Hirt, H. 2004. Reactive oxygen species: metabolism, oxidative stress, and signal transduction. Annual Review of Plant Biology 55: 373-399.

Araujo, A.C.F.B. \& Barbedo, C.J. 2017. Changes in desiccation tolerance and respiratory rates of immature Caesalpinia echinata Lam. seeds. Journal of Seed Science 39: 123-132.

Asomaning, J.M., Olympio, N.S. \& Sacande, M. 2011. Desiccation sensitivity and germination of recalcitrant Garcinia kola Heckel seeds. Research Journal of Seed Science 4: 15-27.

Bailey-Serres, J. \& Mittler, R. 2006. The roles of reactive oxygen species in plant cells. Plant Physiology 141: 311. 
Bailly, C. 2004. Active oxygen species and antioxidants in seed biology. Seed Science Research 14: 93-107.

Bailly, C., Benamar, A., Corbineau, F. \& Côme, D. 1998. Free radical scavenging as affected by accelerated aging and subsequent priming in sunflower seeds. Physiologia Plantarum 104: 646-652.

Bailly, C., El-Maarouf-Bouteau, H. \& Corbineau, F. 2008. From intracellular signaling networks to cell death: the dual role of reactive oxygen species in seed physiology. Comptes Rendus Biologies 331: 806-814.

Barbedo, C.J. 2018. A new approach towards the so-called recalcitrant seeds. Journal of Seed Science 40: 221-236.

Barbedo, C.J., Centeno, D.C. \& Figueiredo-Ribeiro, R.C.L. 2013. Do recalcitrant seeds really exist? Hoehnea 40: 583-593.

Barbosa, J.M., Barbosa, L.M., Rodrigues, M.A., Barbosa, K.C. \& Souza Junior, C.N. 2018. Mercado e políticas públicas para fomentar a produção de sementes de espécies nativas: o Estado de São Paulo como exemplo. In: Barbedo, C.J. \& Santos Junior, N.A. (orgs.) Sementes do Brasil: produção e tecnologia para espécies da flora brasileira. Instituto de Botânica, São Paulo. pp. 161-176.

Barroso, G.M., Morim, M.P., Peixoto, A.L. \& Ichaso, C.L.F. 1999. Frutos e sementes: morfologia aplicada à sistemática de dicotiledôneas. Editora UFV, Viçosa.

Beech, E., Rivers, M., Oldfield, S. \& Smith, P.P. 2017. GlobaTreeSearch: the first complete global database of tree species and country distributions. Journal of Sustainable Forestry 36: 454-489.

Berg, O. 1855. Revisio Myrtacearum Americae. Linnaea 27: $1-128$.

Berg, O. 1856. Revisio Myrtacearum Americae. Linnaea 27: $129-384$.

Berg, O. 1857. Myrtaceae. In: C.P.F. Martius (ed.). Flora Brasiliensis 14: 1-468.

Berg, O. 1858. Myrtaceae. In: C.P.F. Martius (ed.). Flora Brasiliensis 14: 469-528.

Berg, O. 1859. Myrtaceae. In: C.P.F. Martius (ed.). Flora Brasiliensis 14: 529-656.

Berg, O. 1861. Revisio Myrtacearum Americae. Linnaea 30: 647-713.

Berg, O. 1862. Mantissa III. ad Revisionem Myrtacearum Americae. Linnaea 31: 247-262.

Benson, E.E. 1990. Free radical damage in stored plant germplasm. Roma, International Board for Plant Genetic Resources.

BFG (Brazil Flora Group). 2015. Growing knowledge: An overview of seed plant diversity in Brazil. Rodriguésia 66: 1085-1113.

Blokhina, O., Virolainen, E. \& Fagerstedt, K.V. 2003. Antioxidants, oxidative damage and oxygen deprivation stress: a review. Annals of Botany 91: 179-194.
Bogatek, R., Gawronska, H. \& Oracz, K. 2003. Involvement of oxidative stress and $\mathrm{ABA}$ in $\mathrm{CN}$ mediated elimination of embryonic dormancy in apple. In: Nicolas, G., Bradford, K.J., Come, D. \& Pritchard, H.W. (Eds.), The Biology of Seeds: Recent Research Advances. CABI Publishing, Wallingford.

Borisjuk, L. \& Rolletschek, H. 2009. The oxygen status of the developing seed. New Phytologist 182: 17-30.

Breusegem, F.V., Vranova, E., Dat, J.F. \& Inze, D. 2001. The role of active oxygen species in plant signal transduction. Plant Science 161: 405-414.

Brown, T.L., LeMay, H.E., Bursten, B.E., Murphy, C.J. \& Woodward, P.M. 2012. Chemistry, the central science. 12ed. Pearson Prentice Hall, Nova Jersey.

Cadeias, M.O.R. 2019. Agroalimentares sob o enfoque da soberania e segurança alimentar e nutricional: uma construção a partir do estudo de cadeias de frutas nativas da mata atlântica. Tese de Doutorado, Universidade Federal do Rio Grande do Sul, Porto Alegre.

Cadenas, E. 1989. Biochemistry of oxygen toxicity. Annual Review of Biochemistry 58: 79-110.

Calvi, G.P., Aud, F.F., Ferraz, I.D.K., Pritchard, H.W. \& Kraner, I. 2016. Analyses of several seed viability markers in individual recalcitrant seeds of Eugenia stipitata McVaugh with totipotent germination. Plant Biology 19: 6-13

Chance, B., Boveris, A., Oshino, N. \& Loschen, G. 1973. The nature of catalase intermediate and its biological function. In: King, T.E., Mason, H.S., Morrison, M. Oxidases and related redox systems. University Park Press, Baltimore. pp. 350-353.

Cheng, H.Y. \& Song, S.Q. 2008. Possible involvement of reactive oxygen species scavenging enzymes in desiccation sensitivity of Antiaris toxicaria seeds and axes. Journal of Integrative Plant Biology 50: 1549-1556.

Coelho, A.B., Aguiar, D.R.D. \& Fernandes, E.A. 2009. Padrão de consumo de alimentos no Brasil. Revista de Economia e Sociologia Rural 47: 335-62.

De Candolle, A.P. 1828. Prodromus Systematis Naturalis Regni Vegetabilis. Parte 3. Parisiis, Sumptibus Sociorum Treuttel et Würtz.

Delgado, L.F. 2010. Fracionamento, maturação e origem da capacidade regenerativa de sementes de algumas espécies brasileiras de Eugenia (Myrtaceae). Tese de Doutorado. Instituto de Botânica, São Paulo.

Delgado, L.F. \& Barbedo, C.J. 2007. Tolerância à dessecação de sementes de espécies de Eugenia. Pesquisa Agropecuária Brasileira 42: 265-272.

Delgado, L.F. \& Barbedo, C.J. 2011. Atividade inibidora da germinação em extratos de sementes Eugenia uniflora L. Revista Brasileira de Sementes 33: 463-471. 
Delgado, L.F., Mello, J.I.O. \& Barbedo, C.J. 2010. Potential for regeneration and propagation from cut seeds of Eugenia (Myrtaceae) tropical tree species. Seed Science and Technology 38: 624-634.

Desikan, R., Hancock, J. \& Neill, S. 2005. Reactive oxygen species as signaling molecules. In: Smirnoff, N. (ed.) Antioxidants and reactive oxygen species in plants. Oxford, Blackwell, pp. 169-196.

El-Maarouf-Bouteau, H. \& Bailly, C. 2008. Oxidative signaling in seed germination and dormancy. Plant Signaling and Behavior 3: 175-182.

Elstner, E.F. 1991. Oxygen radicals: biochemical basis for their efficacy. Klin Wochenschr 69: 949-956.

Flores, C.W.B. \& Clement, C.R. 1984. Considerações sobre o araçá-boi (Eugenia stipitata McVaugh, Myrtaceae) na Amazônia brasileira. Anais do $7^{\circ}$ Congresso Brasileiro de Fruticultura. Soe. Bras. Frutic., Florianópolis. p. 167-177.

Flores, E.M. \& Rivera, D.I. 1989. Criptocotilia em algunas dicotiledôneas tropicales. Branesia 32: 19-26.

Fontaine, O., Huault, C., Pavis, N. \& Billard, J.-P. 1994. Dormancy breakate of Hordeum vulgare seeds: effects of hydrogen peroxide and scarification on glutathione level and glutathione reductase activity. Plant Physiol. Biochem 32: 677-683.

Fracassetti, D., Costa, C., Moulay, L. \& Tomás-Barberán, F.A. 2013. Ellagic acid derivatives, ellagitannins, proanthocyanidins and other phenolics, vitamin $\mathrm{C}$ and antioxidant capacity of two powder products from camucamu fruit (Myrciaria dubia). Food Chemistry 139: 578-588.

Franzon, R.C., Carpenedo, S., Viñoly, M.D. \& Raseira, M.C.B. 2018. Pitanga - Eugenia uniflora L. In: Rodrigues, S., Silva, E. \& Brito E. (orgs.) Exotic Fruits Reference Guide. Washington, Academic Press. pp. 333-338.

Gentil, D.F.O. \& Ferreira, S.A.N. 1999. Viabilidade e superação da dormência em sementes de araçá-boi (Eugenia stipitata ssp. sororia). Acta Amazônica 29: 21-31.

Green, M.J. \& Hill, H.A.O. 1984. Chemistry of dioxygen. Methods Enzymol 105: 3-22.

Gurgel, J.T.A. \& Soubihe Sobrinho, J. 1951. Poliembrionia em mirtáceas frutíferas. Bragantia 11: 141-163.

Ha, C.O., Sands, V.E., Soepadmo, E. \& Jong, K. 1988. Reproductive patterns of selected understorey trees in the Malaysian rain forest: the apomictic species. Botanical Journal of the Linnean Society 97: 317-331.

Halliwell, B. 2006. Reactive species and antioxidants: redox biology is a fundamental theme of aerobic life. Plant Physiology 141: 312-322.

Halliwell, B. \& Gutteridge, J.M.C. 2015. Free radicals in biology and medicine. Oxford, Oxford University Press.

Hendry, G.A.F. 1993. Oxygen, free radical processes and seed longevity. Seed Science Research 3: 141-153.
Huang, Y.T., Lowe, D.J., Churchman, G.J., Schipper, L.A., Rawlence, N.J. \& Cooper, A. 2012. Carbon storage and DNA adsorption in allophanic soils and paleosols. In: Hartemink, A.E. \& McSweenry, K. (eds.). Soil carbon. Springer, New York. pp.163-172.

Inocente, M.C. \& Barbedo, C.J. 2019. Germination of Eugenia brasiliensis, E. involucrata, E. pyriformis, and E. uniflora (Myrtaceae) under water-deficit conditions. Journal of Seed Science 41: 76-85.

Ishibashi, Y. \& Iwaya-Inoue, M. 2006. Ascorbic acid suppresses germination and dynamic states of water in wheat seeds. Plant Production Science 9: 172-175.

Ishibashi, Y., Tawaratsumida, T., Kondo, K., Kasa, S., Sakamoto, M., Aoki, N., Zheng, S.H., Yuasa, T. \& Iwaya-Inoue, M. 2012. Reactive oxygen species are involved in gibberellin/abscisic acid signaling in barley aleurone cells. Plant Physiology 158: 1705-1714.

Ishibashi, Y., Tawaratsumida, T., Zheng, S.H., Yuasa, T. \& Iwaya-Inoue, M. 2010. NADPH oxidases act as key enzyme on germination and seedling growth in barley (Hordeum vulgare L.). Plant Production Science 13: 45-52.

Ishibashi,Y., Koda, Y., Zheng, S.H., Yuasa, T. \& IwayaInoue, M. 2013. Regulation of soybean seed germination through ethylene production in response to reactive oxygen species. Annals of Botany 111: 95-102.

Johnson, A.M. 1936. Polyembryony in Eugenia hookeri. American Journal of Botany 23:83- 88.

Joshi, G., Kumar, A.N.A., Gowda, B. \& Srinivasa, Y. B. 2006. Production of supernumerary plants from seed fragments in Garcinia gummi-gutta: evolutionary implications of mammalian frugivory. Current science 91: 372-376.

Jussieu A.L. 1789. Genera plantarum secundum ordines naturales disposita, juxta methodum in Horto Regio Parisiensi exaratum, anno M.DCC.LXXIV. Paris.

Justo, C.F., Alvarenga, A.A., Alves, E., Guimarães, R.M. \& Strassburg, R.C. 2007. Efeito da secagem, do armazenamento e da germinação sobre a micromorfologia de sementes de Eugenia pyriformis Camb. Acta Botanica Brasilica 21: 539-551.

Kasecker, T.P., Ramos-Neto, M.B., Silva, J.M.C. \& Scarano, F.R. 2017. Ecosystembased adaptation to climate change: defining hotspot municipalities for policy design and implementation in Brazil. Mitigation and Adaptation Strategies to Global Change.

Keple, A.W. 2014. O estado da segurança alimentar e nutricional no Brasil: um retrato multidimensional. FAO, Brasília.

Kibinza, S., Vinel, D., Côme, D., Bailly, C. \& Corbineau, F. 2006. Sunflower seed deterioration as related to moisture content during ageing, energy metabolism and active oxygen species scavenging. Physiologia Plantarum 128: 496-506. 
Lamarca, E.V. \& Barbedo, C.J. 2012. Short storability of Caesalpinia echinata Lam. seeds as a consequence of oxidative processes. Hoehnea 39: 577-586.

Landrum, L.R. \& Kawasaki, M.L. 1997. The genera of Myrtaceae in Brazil: an illustrated synoptic treatment and identification keys. Brittonia 49: 508-536.

Leprince, O., Hendry, G.A.F. \& McKersie, B.D.; 1993. Mechanisms of desiccation tolerance in developing seeds. Seed Science Research 3: 231-246.

Litz, R.E. 1984. In vitro responses of adventitious embryos of two polyembryonic Eugenia species. HortScience 19: 720-722.

Lorenzi, H. 2016. Árvores brasileiras: manual de identificação e cultivo de plantas arbóreas nativas do Brasil. v.1. Plantarum: Nova Odessa.

Lucas, E.J., Belsham, S.R., Nic Lughadha, E.M., Orlovich, D.A., Sakuragui, C.M., Chase, M.W. \& Wilson, P.G. 2005. Phylogenetic patterns in the fleshyfruited Myrtaceae - preliminary molecular evidence. Plant Systematics and Evolution 251: 35-51.

Lughadha, E.N. \& Proença, C. 1996. A survey of the reproductive biology of the Myrtoideae (Myrtaceae). Ann. Missouri Bot. Gard. 83: 480-503.

Malik, S. K., Chaudhury, R. \& Abraham, Z. 2005. Desiccation-freezing sensitivity and longevity in seeds of Garcinia indica, G. cambogia and G. xanthochymus. Seed Science and Technology 33: 723-732.

Marcos-Filho, J. 2015. Fisiologia de sementes de plantas cultivadas. ABRATES, Londrina.

Mazine, F.F., Faria, J.E.Q., Giaretta, A., Vasconcelos, T., Forest, F. \& Lucas, E. 2018. Phylogeny and biogeography of the hyper-diverse genus Eugenia (Myrtaceae: Myrteae), with emphasis on E. sect. Umbellatae, the most unmanageable clade. Taxon 67: 752-769.

McVaugh, R. 1956. Tropical american Myrtaceae: notes on generic concepts and descriptions of previously unrecognized species. Fieldiana Botany 29: 145-228.

Mittler, R., Vanderauwera, S., Gollery, M. \& Breusegem, F.V. 2004. Reactive oxygen gene network of plants. Trends in Plant Science 9: 490-498.

Moller, I. M. 2001. Plant mitochondria and oxidative stress: electron transport, NADPH turnover, and metabolism of reactive oxygen species. Annu. Rev. Plant Physiol. Plant Mol. Biol. 52: 561-591.

Moothoo-Padayachie, A., Varghese, B., Pammenter, N.W. \& Sershen, P.G. 2016. Germination associated ROS production and glutathione redox capacity in two recalcitrant-seeded species differing in seed longevity. Botany 94: 1103-1114.

Naredo, M.E.B., Juliano, A.B., Lu, B.R., Guzman, F.D. \& Jackson, M.T. 1998. Responses to seed dormancybreaking treatments in rice species (Oryza L.). Seed Sci. Technol. 26: 675-689.
Ofori, D.A., Asomaning, J.M., Peprah, T., Agyeman, V.K., Anjarwalla, P., Tchoundjeu, Z., Mowo, J.G. \& Jamnadass, R. 2015. Addressing constraints in propagation of Allanblackia spp. through seed sectioning and air layering. Journal of Experimental Biology and Agricultural Sciences 3: 89-96.

Ogawa, K. \& Iwabuchi, M. 2001. A mechanism for promoting the germination of Zinnia elegans seeds by hydrogen peroxide. Plant and Cell Physiology 42: 286-291.

Okuda, T., Yoshida, T., Hatano, T., Yazaki, K. \& Ashida, M. 1982. Ellagitannins of the Casuarinaceae, Stachyuraceae and Myrtaceae. Phytochemistry 21: 2871-2874.

Oracz, K., El-Maarouf Bouteau, H., Farrant, J.M., Cooper, K., Belghazi, M., Job, C., Job, D., Corbineau, F. \& Bailly, C. 2007. ROS production and protein oxidation as a novel mechanism for seed dormancy alleviation. The Plant Journal 50: 452-465.

Oracz, K., El-Maarouf-Bouteau, H., Kranner, I., Bogatek, R., Corbineau, F. \& Bailly, C. 2009. The mechanisms involved in seed dormancy alleviation by hydrogen cyanide unravel the role of reactive oxygen species as key factors of cellular signaling during germination. Plant Physiol. 150: 494-505.

Pereira, M.C., Boschetti, W., Rampazzo, R., Celso, P.G., Hertz, P.F., Rios, A.O., Vizzotto, M. \& Flores, S.H. 2014. Mineral characterization of native fruits from the southern region of Brazil. Food Science and Technology 34: 258-266.

Pereira, M.C., Steffens, R.S., Jablonski, A., Hertz, P.F., Rios, A.O., Vizzotto, M. \& Flôres, S.H. 2012. Characterization and antioxidant potential of brazilian fruits from the Myrtaceae family. Journal of Agriculture and Food Chemistry 60: 3061-3067.

Piña-Rodrigues, F.C.M., Urzedo, D.I., Corrêa, A.J.M. \& Figliolia, M.B. 2018. O futuro das sementes nativas. In: Barbedo, C.J. \& Santos Junior, N.A. (orgs.) Sementes do Brasil: produção e tecnologia para espécies da flora brasileira. Instituto de Botânica, São Paulo. pp. 177-207.

Prataviera J.S., Lamarca E.V., Teixeira C.C. \& Barbedo, C.J. 2015. The germination success of the cut seeds of Eugenia pyriformis depends on their size and origin. Journal of Seed Science 37: 47-54.

Pukacka, S. \& Ratajczak, E. 2006. Antioxidative response of ascorbate-glutathione pathway enzymes and metabolites to desiccation of recalcitrant Acer saccharinum seeds. Journal of Plant Physiology 163: 1259-1266.

Puntarulo, S.; Sánchez, R.A. \& Boveris, A. 1988. hydrogen peroxide metabolism in soybean embryonic axes at the onset of germination. Plant Physiol 86: 626-630.

Ratnam, D., Ankola, D., Bhardwaj, V., Sahana, D. \& Kumar, M. 2006. Role of antioxidants in prophylaxis and therapy: a pharmaceutical perspective. Journal of Controlled Release 113: 189-207. 
Reynertson, K.A., Yang, H., Jiang, B., Basile, M.J. \& Kennelly, E.J. 2008. Quantitative analysis of antiradical phenolic constituents from fourteen edible Myrtaceae fruits. Food Chemistry 109: 883-890.

Rizzini, C.T. 1970. Efeito tegumentar na germinação de Eugenia dysenterica DC. (Myrtaceae). Revista Brasileira de Biologia 30: 381-402

Roach T., Beckett R.P., Minibayeva, F.V., Colville, L., Whitaker, C., Chen, H., Bailly, C. \& Kranner, I. 2010. Extracellular superoxide production, viability and redox poise in response to desiccation in recalcitrant Castanea sativa seeds. Plant Cell Environ 33:59-75.

Schopfer, P., Plachy, C. \& Frahry, G. 2001. Release of reactive oxygen intermediates (superoxide radicals, hydrogen peroxide, and hydroxyl radicals) and peroxidase in germinating radish seeds controlled by light, gibberellin, and abscisic acid. Plant Physiology 125: 1591-1602.

Sies, H. 1997. Oxidative stress: oxidants and antioxidants. Experimental Physiologv 82: 291-295.

Silva, A.P.G., Freitas, T.P., Morais, V.S.P. \& Jacomino, A.P. 2018. Uvaia - Eugenia pyriformis Cambess. In: Rodrigues, S., Silva, E. \& Brito E. (orgs.) Exotic Fruits Reference Guide. Washington, Academic Press. pp. 435-438.

Silva, C.V., Bilia, D.A.C. \& Barbedo, C.J. 2005. Fracionamento e germinação de sementes de Eugenia. Revista Brasileira de Sementes 27: 86-92.

Silva, C.V., Bilia, D.A.C., Maluf, A.M. \& Barbedo, C.J. 2003. Fracionamento e germinação de sementes de uvaia (Eugenia pyriformis Cambess. - Myrtaceae). Revista Brasileira de Botânica 26: 213-221.

Souza, V.C. \& Lorenzi, H. 2012. Botânica sistemática: guia ilustrado para identificação das famílias de fanerógamas nativas e exóticas no Brasil, baseado em APG III. $3^{\mathrm{a}}$ ed. Instituto Plantarum, Nova Odessa.
Staniek K. \& Nohl H. 2000. Are mitochondria a permanent source of reactive oxygen species? Biochimica et Biophysica Acta 1460: 268-75.

Steinmetz, K.A. \& Potter, J.D. 1996. Vegetables, fruits, and cancer prevention: a review. Journal of the Academy of Nutrition and Dietetics 96: 1027-1039.

Su, L., Lan, Q., Pritchard, H.W., Xue, H. \& Wang, X. 2016. Reactive oxygen species induced by cold stratification promote germination of Hedysarum scoparium seeds. Plant Physiology and Biochemistry 109: 406-415.

Teixeira, C.C. \& Barbedo, C.J. 2012. The development of seedlings from fragments of monoembryonic seeds as an important survival strategy for Eugenia (Myrtaceae) tree species. Trees, Structure and Function 26: 1069-1077.

Teixeira, L.L., Hassimotto, N.M.A. \& Lajolo, F.M. 2018. Grumixama - Eugenia brasiliensis Lam. In: Rodrigues, S., Silva, E. \& Brito E. (orgs.) Exotic Fruits Reference Guide. Washington, Academic Press. pp. 219-224.

Tommasi, F., Paciolla, C. \& Arrigoni, O. 1999. The ascorbate system in recalcitrant and orthodox seeds. Physiologia Plantarum 105: 193-198.

Turrens, J.F. 2003. Mitochondrial formation of reactive oxygen species. Journal of Plant Physiology. 15: 335-44.

Van Wyk, A.E. \& Botha, R. 1984. The genus Eugenia (Myrtaceae) in southern Africa: ontogeny and taxonomic value of the seed. South African Journal of Botany 3: 63-80.

Varghese, B., Sershen, Berjak, P., Varghese, D., \& Pammenter, N.W. 2011. Differential drying rates of recalcitrant Trichilia dregeana embryonic axes: a study of survival and oxidative stress metabolism. Physiol Plant 142: 326-338.

WCSP(World Checklist of Selected Plant Families). 2017. World checklist of selected plant families. Available in http://www.kew.org/wcsp/myrtaceae (access in 10-II2020). 